\title{
Effects of Seawater Corrosion and Freeze-Thaw Cycles on Mechanical Properties of Fatigue Damaged Reinforced Concrete Beams
}

\author{
Zijian Liu, ${ }^{1,2}$ Bo Diao, ${ }^{1}$ and Xiaoning Zheng ${ }^{1,2}$ \\ ${ }^{1}$ School of Transportation Science and Engineering, Beihang University, Beijing 100191, China \\ ${ }^{2}$ State Laboratory of Subtropical Building Science, South China University of Technology, Guangzhou 510640, China
}

Correspondence should be addressed to Xiaoning Zheng; zhengxn1974@163.com

Received 29 April 2015; Revised 20 July 2015; Accepted 22 July 2015

Academic Editor: Robert Cerný

Copyright (C) 2015 Zijian Liu et al. This is an open access article distributed under the Creative Commons Attribution License, which permits unrestricted use, distribution, and reproduction in any medium, provided the original work is properly cited.

\begin{abstract}
The effects of seawater corrosion and freeze-thaw cycles on the structural behavior of fatigue damaged reinforced concrete (FDRC) beams were experimentally studied. Results show that the residual strength of FDRC beams reduces as the fatigue load level (the ratio of maximum fatigue load to the ultimate static load) increases. The reduction in the loading capacity of FDRC beams in atmosphere environment was about $6.5 \%$ and $17.8 \%$ for given fatigue load levels of 0.2 and 0.3 , respectively. However, if FDRC beams are exposed to the environment of seawater wet-dry cycles or to the environment of alternating actions of freeze-thaw and seawater immersion, as expected during the service life of RC bridge structures in coastal regions or in cold coastal regions, a more rapid reduction in the strength and stiffness of the beams is observed. The significance of an accurate simulation of working load and service condition RC bridge structures in coastal regions and cold coastal regions is highlighted.
\end{abstract}

\section{Introduction}

The bearing capacity and durability of in-service reinforced concrete (RC) bridges may gradually deteriorate due to traffic loads. In particular, the expected service life of fatigue damaged RC (FDRC) bridges in cold coastal region may be greatly reduced by chloride corrosion and freeze-thaw cycles. For example, severe cracking and steel corrosion [1] have been found in some RC bridges in coastal Shandong province in China. Although these bridges have serviced for only ten years, the loading capacity and durability of the bridges have greatly degraded due to the harsh environment.

The fatigue behavior and mechanism of RC structures have been investigated over the last century. Chang and Kesler [2] tested the fatigue capacity of RC beams and concluded that the fatigue fracture model was quite different with the variation of fatigue stress level. Ople and Hulsbos [3] experimentally confirmed that the fatigue strength of compression concrete in RC beams was higher than that of the axial compression concrete in column with the same concrete mixture. The testing results by Tepfer et al. [4] showed that, comparing with a sinusoidal triangular waveform, a rectangular waveform can result in a shorter fatigue life. Schläfli and Brühwiler [5] verified that the likelihood of RC bridges failure caused by fatigue compressing fracture was low and the current fatigue design methods were satisfactory. Existing researches of fatigue performance were focused on the fatigue life of RC structure, and few studies have been found on the bearing capacity deterioration of structure by cyclic loading. Muir and Bennett [6] experimentally studied the influence of the static strength and the maximum size of coarse aggregate upon the fatigue strength at 1,000,000 cycles and found the "run-out" specimens showed a marked increase in static strength comparing with those that were not cyclically fatigued. Award and Hilsdorf [7] studied the influence of maximum fatigue stress, fatigue stress amplitude, and age of concrete on the mechanical properties of concrete prism specimens, and the result showed that the residual static strength of concrete increased in the top 30\% of the fatigue life of concrete and then decreased. Talreja and Weibull [8] reported that the residual strength of the steel specimens decreased as the number of loading cycles increased. Ling and 
TABLE 1: Concrete $\mathrm{mix} /\left(\mathrm{kg} / \mathrm{m}^{3}\right)$.

\begin{tabular}{lccccccc}
\hline Water & Cement & Sand & Coarse aggregates & Fly ash & Superplasticizer & Air entraining agent \\
\hline 184.4 & 468.8 & 625 & 1156.3 & 37.5 & 3.1 & 0.94 & \\
\hline
\end{tabular}

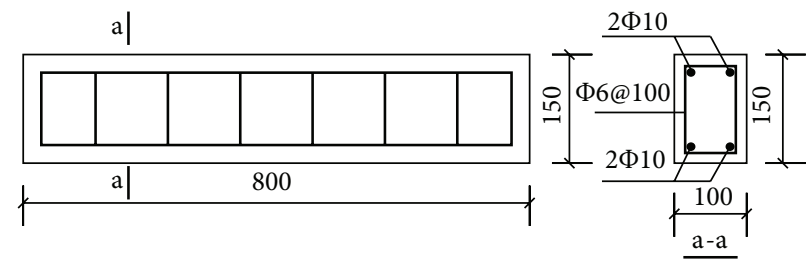

FIGURE 1: Reinforcement detailing of beams.

Li [9] confirmed that the residual strength of steel decreased as the number of loading cycles increased, indicating that the relaxation of the residual strength of steel in the early stage of fatigue loading cannot be ignored.

Recent studies indicate that the working environment of RC structures has a significant impact on the fatigue behavior. Erosion environment can greatly reduce the fatigue life of RC structures [10]. Radian [11] studied the fatigue life of $\mathrm{RC}$ beams under air environment, saltwater environment, and saltwater freezing and thawing environment. The results showed that the coupling action of service environment and fatigue load level (in the range of 0.41 to 0.92 ) had a great influence on the fatigue lives of RC beams. Al-Hammoud et al. [12] tested galvanic corroded $\mathrm{RC}$ beams under monotonic loading and fatigue loading and showed that the rate of corrosion affected the fatigue lives of RC beams. Wang and Gong [13] tested the deformation and fatigue lives of $\mathrm{RC}$ beams in the air, freshwater, and saltwater conditions, respectively, and observed that the fatigue lives under the air, freshwater, and saltwater conditions were 2,000,000, 910,000, and 330,000, respectively, when the fatigue load level was 0.55 .

Yuan et al. [14] studied the effects of freeze-thaw cycles on concrete pores by X-ray CT and results indicated that frost failure gradually developed from surface to interior of concrete specimens as the number of freeze-thaw cycles increases. Diao et al. [15] performed testing for cracked RC beams under the environment of alternating seawater wetdry and freeze-thaw cycles. The results showed that seawater erosion and freezing-thawing could accelerate the deterioration of RC beams, and the contribution from freezing and thawing was larger than that of pure seawater erosion.

Most of the existing studies focus on the experimental investigation of the fatigue limit of RC structures with a fatigue load level that is usually larger than 0.40 . Few studies have been focused on the fatigue durability of RC structures under the practical working condition. In this study, the actual working condition of RC bridges was simulated using the following steps. First, RC beams were fatigue loaded at different load levels with a prescribed number of cycles. Next, RC beams were exposed to the seawater wet-dry environment or to the alternative environment of freeze-thaw cycles. Finally, the RC beams were statically tested and the performance degradation of the beams was studied.

\section{Specimen Design and Testing Procedures}

2.1. Specimen Design. The practical working condition was simulated here to investigate the fatigue durability of RC structures. The comprehensive effects of fatigue damage and environment were considered. The low fatigue load levels $(0.0,0.2$, and 0.3$)$ were selected. The maximum number of fatigue loading cycles was determined as 200,000 to represent the early stage of the fatigue life of RC beams. Next, the FDRC beams were exposed to the environment conditions of air, seawater wet-dry cycles, and alternations of freeze-thaw and seawater immersion, respectively. The effects of fatigue load level and working environments on residual strength of RC beams were studied by static loading test.

Two sets of specimens were prepared. The first set consists of a total of 9 plain concrete specimens for material property tests. The second set includes $20 \mathrm{RC}$ beams for structural deterioration tests. Parameters of the concrete mix are shown in Table 1. The mix has a maximum aggregate size of $8 \mathrm{~mm}$ and a gas content of $5.4 \%$.

Nine plain concrete specimens were made and were equally divided into three groups. The first group was exposed to an environment of seawater wet-dry cycles. The second group was exposed to an alternating environment of freezethaw and seawater immersion. The third group was exposed to the air as a reference. The dimensions for all specimens were $100 \mathrm{~mm} \times 100 \mathrm{~mm} \times 100 \mathrm{~mm}$.

All RC beam specimens had the same dimensions of $b \times h \times$ $l=100 \mathrm{~mm} \times 150 \mathrm{~mm} \times 800 \mathrm{~mm}$ and the same arrangement of reinforcement bars. The reinforcement details are shown in Figure 1. The longitudinal reinforcement of beams has a size of $2 \Phi 10$; the reinforcement ratio is of $1.05 \%$.

A reference beam specimen was tested with a static loading at the age of 176 days, and the ultimate load was obtained as $P_{u}=47.5 \mathrm{kN}$. To study the effects of fatigue load level and working environments on residual strength of $\mathrm{RC}$ beams, the remaining 19 specimens were divided into 9 groups according to three fatigue loading levels and three environment conditions. The three fatigue loading levels were $0.0,0.2$, and 0.3 , respectively. And the three environment conditions were air, seawater wet-dry, and alternating freeze-thaw and seawater immersion, respectively. Denote the beams in the air as A series, in the seawater wet-dry 
TABLE 2: Testing parameters of beam specimens.

\begin{tabular}{|c|c|c|c|c|c|c|}
\hline \multirow{2}{*}{ Series number } & \multirow{2}{*}{ Groups number } & \multirow{2}{*}{ Specimen number } & \multicolumn{2}{|c|}{ Fatigue load } & \multirow{2}{*}{ Loading cycles } & \multirow{2}{*}{ Environment condition } \\
\hline & & & Upper & Lower & & \\
\hline \multirow{3}{*}{ A } & 1 & $\mathrm{~A} 1, \mathrm{~A} 2$ & 0 & 0 & 0 & Air \\
\hline & 2 & $\mathrm{~A} 3, \mathrm{~A} 4$ & $0.2 P_{u}$ & $0.1 P_{u}$ & $2 \times 10^{6}$ & Air \\
\hline & 3 & A5, A6 & $0.3 P_{u}$ & $0.1 P_{u}$ & $2 \times 10^{6}$ & Air \\
\hline \multirow{3}{*}{ B } & 4 & $\mathrm{~B} 1, \mathrm{~B} 2$ & 0 & 0 & 0 & Wet-dry \\
\hline & 5 & B3, B4 & $0.2 P_{u}$ & $0.1 P_{u}$ & $2 \times 10^{6}$ & Wet-dry \\
\hline & 6 & $\mathrm{~B} 5, \mathrm{~B} 6$, and $\mathrm{B} 7$ & $0.3 P_{u}$ & $0.1 P_{u}$ & $2 \times 10^{6}$ & Wet-dry \\
\hline \multirow{3}{*}{$\mathrm{C}$} & 7 & $\mathrm{C} 1, \mathrm{C} 2$ & 0 & 0 & 0 & Freeze-thaw \\
\hline & 8 & $\mathrm{C} 3, \mathrm{C} 4$ & $0.2 P_{u}$ & $0.1 P_{u}$ & $2 \times 10^{6}$ & Freeze-thaw \\
\hline & 9 & $\mathrm{C} 5, \mathrm{C} 6$ & $0.3 P_{u}$ & $0.1 P_{u}$ & $2 \times 10^{6}$ & Freeze-thaw \\
\hline
\end{tabular}

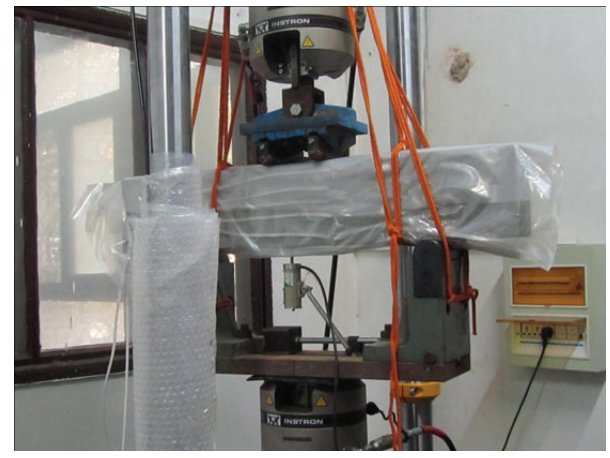

FIGURE 2: Setup of fatigue loading device.

as B series, and in alternating freeze-thaw and seawater immersion as $\mathrm{C}$ series. Details of testing parameters for each of the groups are shown in Table 2.

2.2. Test Procedures. All tests were performed in the Civil Engineering Laboratory and the Fatigue Laboratory at Beihang University in Beijing. All specimens were demolded after 24 hours of casting and were cured under standard temperature and moisture conditions. The beam specimens of 9 groups (three series) at the age of 180 days were cyclically loaded on MTS fatigue testing machine for 200,000 cycles. The detailed loading parameters are shown in Table 2 , and the loading setup is shown in Figure 2. Four-point bending sine wave with a frequency of $5 \mathrm{~Hz}$ was used. The loading process was automatically controlled by a computer.

Environment simulation of FDRC beam specimens was carried out after fatigue testing. Beam specimens of A series were placed in the air for 100 days, specimens of B series were exposed to seawater wet-dry cycles, and specimens of $\mathrm{C}$ series were exposed to alternative actions of seawater immersed and freeze-thaw cycles. The procedure of seawater wet-dry cycles was designed to immerse the specimens in seawater for $12 \mathrm{~h}$ and then expose the specimens to the air for $12 \mathrm{~h}$ as one cycle. The procedure was repeated until 100 cycles were finished. The procedures of alternative actions of seawater immersed and freeze-thaw cycles were 300 freeze-thaw cycles and 100 times of seawater immersion, as described by Diao et al. [15].
The seawater used in current study was the artificial mixed solution of sodium chloride $(\mathrm{NaCl})$ and magnesium sulfate $\left(\mathrm{MgSO}_{4}\right)$ with a mass ratio of $3 \%$ and $0.34 \%$, respectively.

All beam specimens except B7 were statically loaded until failure, while the rebar in the beam specimen B7 was tested by monotonous tension. The static loading terminated when one of the three conditions was met: the tensile reinforcement fractured, the ultimate load was decreased by the amount of $15 \%$, and the middle deflection was larger than $1 / 50$ of the beam span.

\section{Results and Discussion}

\subsection{Material Test Results}

3.1.1. Compressive Strength of Plain Concrete. Table 3 shows the compressive strength of concrete specimens. Comparing with the specimens of the reference group, the average compressive strength of the specimens after seawater wet-dry cycles (100 times) decreased by $1.9 \%$. The average compressive strength of the specimens after alternating freeze-thaw (300 times) and seawater immersion (100 times) decreased by $8.1 \%$. This means that seawater wet-dry cycles (100 times) have no significant impact on the compressive strength of concrete specimens, and, due to the discreteness, the compressive strength of specimen a-3 under air condition is a little bit lower than b-1 and b-2 under seawater condition.

3.1.2. Strength of Rebar Specimens. The four rebar specimens were tested by monotonous tension, named reference group in Table 4. And two rebar specimens in the FDRC beam specimen B7, named fatigue group, were also tested; the rebar shown in Figure 3 was cut from specimen B7 (the remaining strength of B7 was not tested, but seawater wet-dry cycles condition for B7 was the same with B5 and B6). The strength of all rebar specimens was listed in Table 4.

Since there was no yielding point in the stress-strain curves of the reference group rebar, the yield strength was taken as the stress corresponding to $0.2 \%$ residual strain according to the Chinese code for design of concrete structures (GB 50010-2010). It can be seen from Table 4 that the yield strength of rebar specimens decreased significantly after 
TABLE 3: Compression strength of concrete.

\begin{tabular}{lcc}
\hline Series & $\begin{array}{c}\text { Compressive } \\
\text { strength/MPa }\end{array}$ & Average/MPa \\
\hline $\begin{array}{l}\text { Reference } \\
\text { group }\end{array}$ & & \\
a-1 & 42.0 & 42.1 \\
a-2 & 43.5 & \\
a-3 & 40.9 & \\
Seawater wet-dry & & \\
cycle group & & \\
b-1 & 41.9 & \\
b-2 & 41.7 & \\
b-3 & 40.2 & \\
Seawater freeze-thaw & & \\
cycle group & & \\
c-1 & 38.0 & \\
c-2 & 38.9 & \\
c-3 & 39.2 & \\
\hline
\end{tabular}

TABLE 4: Strength of rebar specimens.

\begin{tabular}{lccc}
\hline Series & $\begin{array}{c}\text { Number of } \\
\text { rebar }\end{array}$ & $\begin{array}{c}\text { Yield } \\
\text { strength/MPa }\end{array}$ & $\begin{array}{c}\text { Ultimate } \\
\text { strength/MPa }\end{array}$ \\
\hline \multirow{2}{*}{ Reference } & 1 & 560 & 705 \\
group & 2 & 545 & 735 \\
& 3 & 552 & 736 \\
Fatigue & 4 & 532 & 720 \\
group & Fatigue 1 & 481 & 710 \\
\hline
\end{tabular}

fatigue loading, but the ultimate strength has no significant variation.

The strain-stress curves shown in Figure 4 indicate that the elastic modulus for each of the groups was almost the same, with an average of $E_{s}=248 \mathrm{GPa}$. The residual yield strength and ductility of rebars in the fatigue group reduced at the fatigue load level of 0.3 . The ultimate stress remains at the same level in the strain range of $2000 \mu \varepsilon-6000 \mu \varepsilon$. It should be noted that Talreja and Weibull [8] and Ling and $\mathrm{Li}$ [9] also reported that the residual strength of steel specimens monotonically decreased as the number of fatigue load cycles increased based on numerous test data and statistical regression. This agrees well with the conclusion drawn from this case study that the residual yielding strength of fatigue bars decreased.

3.2. Fatigue Bending Loading. The fatigue load level for beam specimens A3, A4, B3, B4, C3, and C4 was 0.2. All these specimens showed a crack at the bottom of middle span within the first 200 cycles of loading. Cracks initiated from the bottom were propagated to the location of the tensile reinforcement ( $40 \mathrm{~mm}$ from the bottom of the beam). As the number of cycles increased, a second crack appeared parallel to the first crack. The crack lengths of the two cracks were

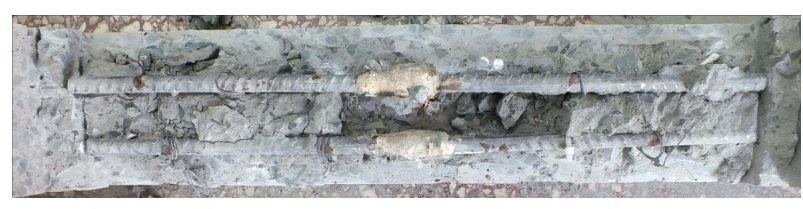

FIgure 3: Tensile rebar in beam specimen B7.

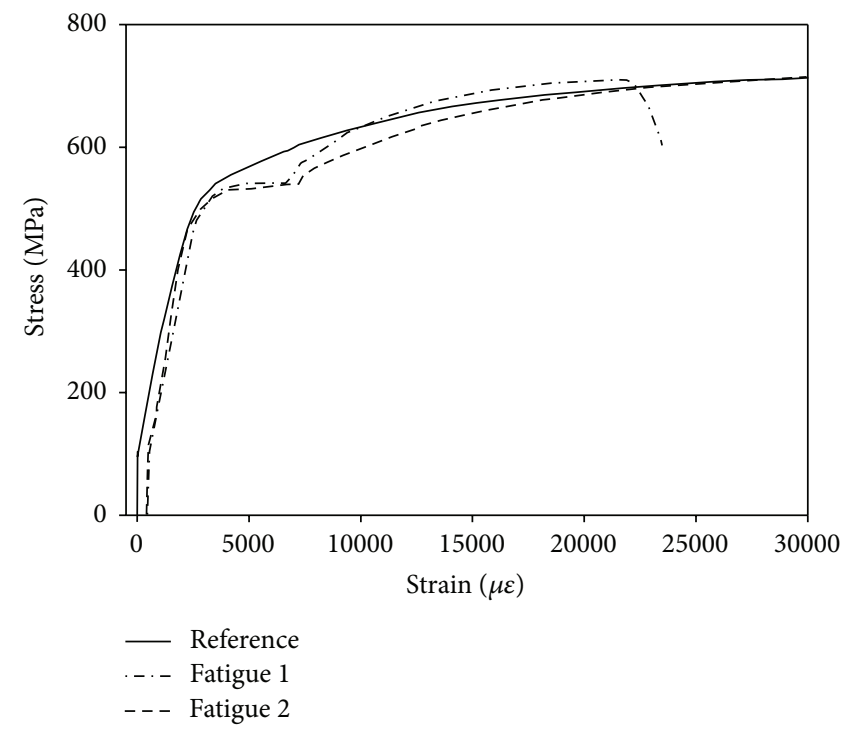

FIGURE 4: Stress-strain curves of rebar from reference and fatigue group.

almost identical. The maximum fatigue load level for A5, A6, $\mathrm{B} 5, \mathrm{~B} 6, \mathrm{~B} 7, \mathrm{C} 5$, and $\mathrm{C} 6$ was 0.3 . All these beam specimens developed a crack at the bottom of middle span in the first cycle. Cracks propagated from the bottom up to the location of compression reinforcement $(110 \mathrm{~mm}$ above the bottom of the beam). With continuous loading parallel cracks appeared near the first crack. The lengths of the new cracks were shorter than the first crack. Figure 5 shows the fatigue cracks of specimen A6. The width and length of cracks and the total number of cracks are shown in Table 5. It can be observed that with the increasing load the number of cracks, the length, and the width of cracks also increased.

The relationship of the number of loading cycles and deflection at midspan of beam specimens was shown in Figure 6 at the fatigue load level of 0.2. As shown in Figure 6, the midspan deflection of beam specimens increased rapidly in the first 100 cycles and then slowed down. The average maximum midspan deflection of the specimens was $0.893 \mathrm{~mm}$ in the last cycle and the coefficient of variation (COV) was 0.043 .

The relationship of the number of loading cycles and the maximum tensile strain and residual strain of tensile rebar are shown in Figure 7. It can be seen from Figure 7 that the maximum strain of rebar increased rapidly in the first 1000 loading cycles and increased slightly afterwards. But the residual strain increased faster than the maximum strain; this means that the plastic deformation of tensile rebar gradually 
TABLE 5: Crack condition of beams after fatigue loading.

\begin{tabular}{lcccc}
\hline Number & $\begin{array}{c}\text { Fatigue } \\
\text { load level }\end{array}$ & Number of cracks & Max width of crack/mm & Max length of crack on side/mm \\
\hline A1, A2 & 0 & - & - & - \\
A3 & 0.2 & 2 & 0.07 & 43 \\
A4 & 0.2 & 1 & 0.08 & 41 \\
A5 & 0.3 & 3 & 0.11 & 88 \\
A6 & 0.3 & 3 & 0.21 & 102 \\
B1, B2 & 0 & - & - & - \\
B3 & 0.2 & 2 & 0.12 & 42 \\
B4 & 0.2 & 1 & 0.09 & 49 \\
B5 & 0.3 & 3 & 0.10 & 83 \\
B6 & 0.3 & 2 & 0.10 & 92 \\
B7 & 0.3 & 3 & 0.12 & 101 \\
C1, C2 & 0 & - & - & - \\
C3 & 0.2 & 3 & 0.10 & 41 \\
C4 & 0.2 & 2 & 0.11 & 36 \\
C5 & 0.3 & 4 & 0.12 & 102 \\
C6 & 0.3 & 3 & 0.11 & 124 \\
\hline
\end{tabular}

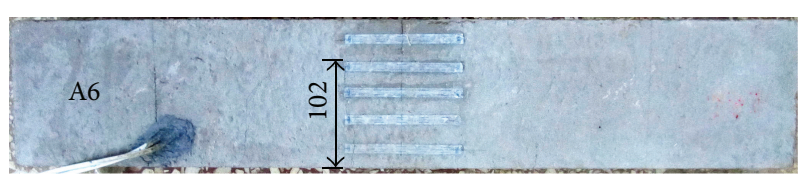

Figure 5: Cracks distribution of beam specimen A6.

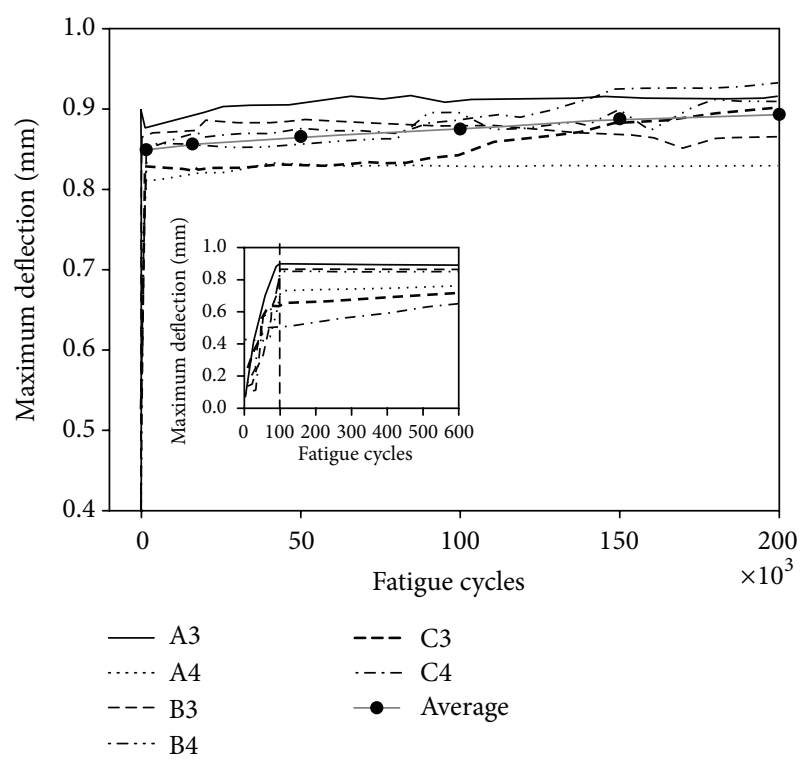

FIgURE 6: Max deflection of beams at load level 0.2.

increased with the cycles of fatigue loading increased. The average maximum strain of tensile rebar was $423 \mu \varepsilon$ in the last cycle and the COV was 0.055 ; the average residual strain of tensile rebar was $145 \mu \varepsilon$ in the last cycle and the COV was 0.148 .

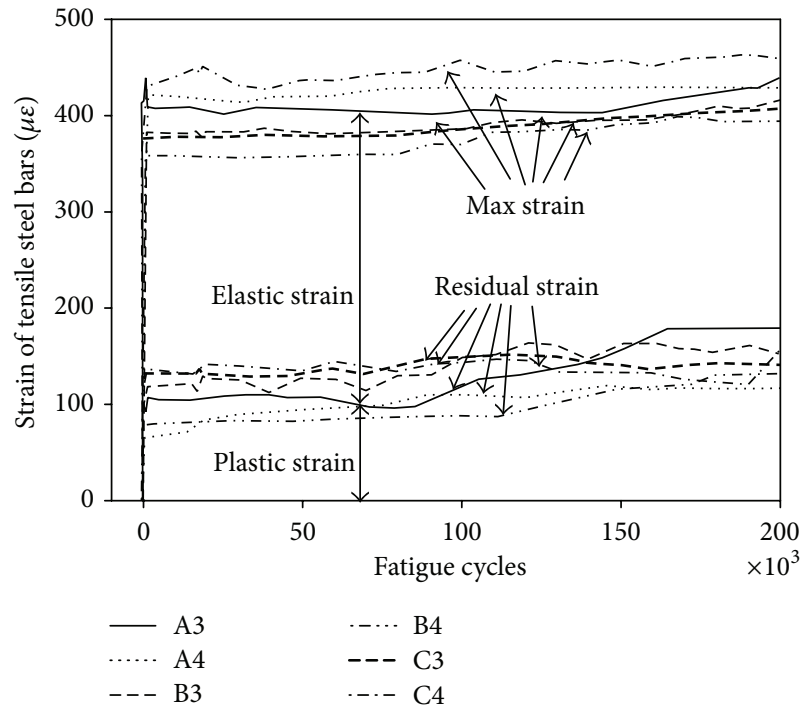

Figure 7: Max and residual strain of rebar at load level 0.2.

The midspan deflection of beams and the strain of tensile rebar are shown in Figures 8 and 9 at the fatigue load level of 0.3 , respectively. Compared with the results at fatigue load level 0.2 , the range of the midspan deflection of beam specimens increased significantly. The curves in Figure 8 showed a large variation of the maximum deflection in terms of amplitude and increasing rate. The average maximum midspan deflection of beams was $1.315 \mathrm{~mm}$ in the last cycle and the COV was 0.110 .

Figure 9 shows that the residual strain of tensile rebar increased slowly when the number of fatigue loading cycles was larger than 1000 . The average maximum strain of tensile rebar was $820 \mu \varepsilon$ in the last cycle and the COV was 0.117 . The 


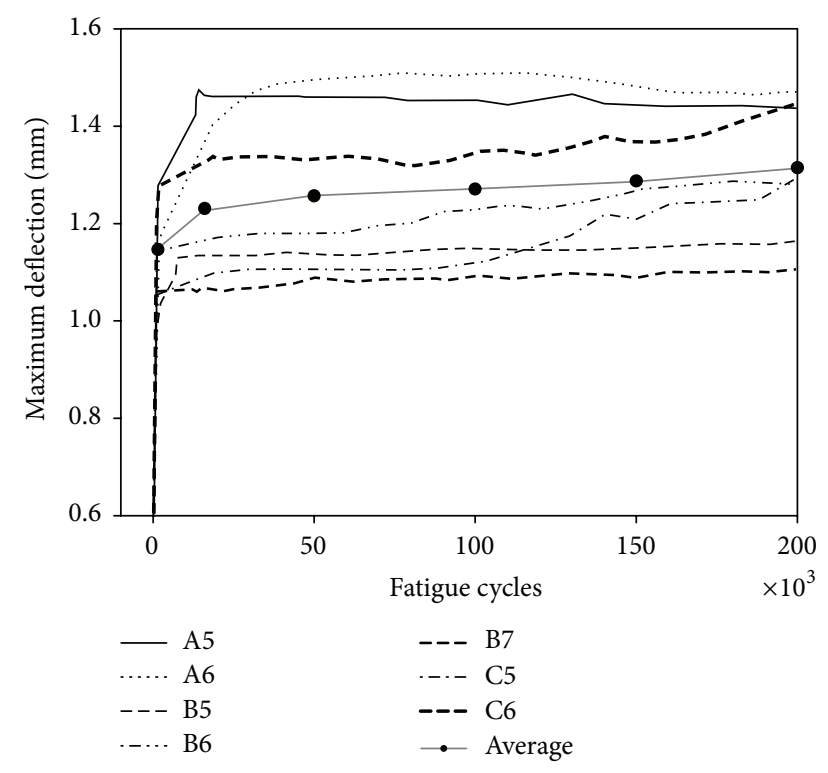

Figure 8: Max midspan deflection at load level 0.3.

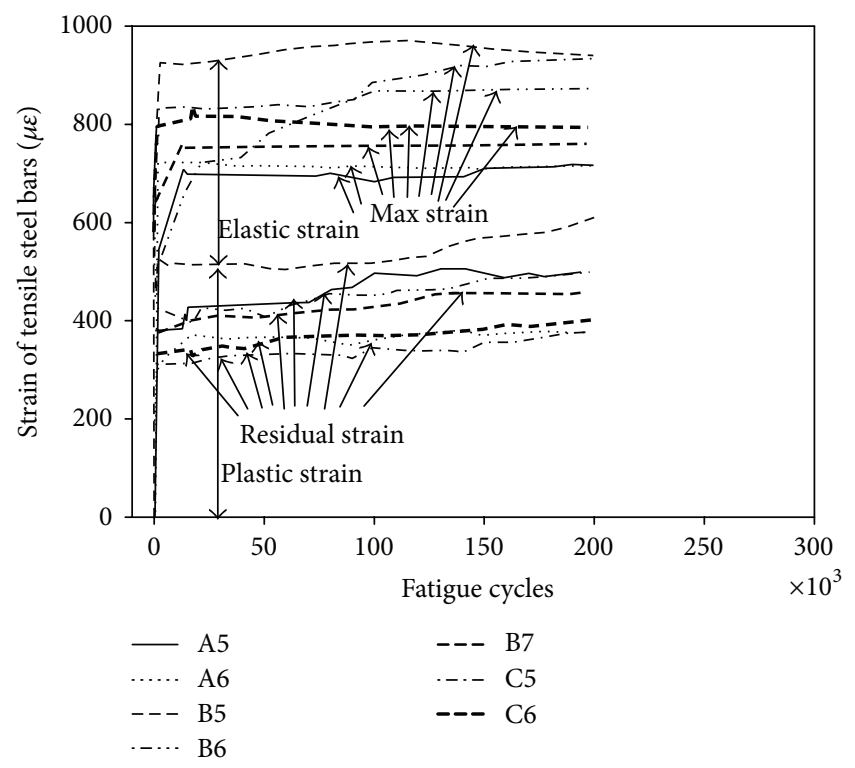

FIGURE 9: Max and residual strain of rebar at load level 0.3.

average residual strain of tensile rebar was $461 \mu \varepsilon$ in the last cycle and the COV was 0.181 .

At the fatigue load level of 0.2 , the COV of the maximum midspan deflection, the maximum tensile strain, and the residual tensile strain of rebar were $0.043,0.055$, and 0.148 , respectively. At the fatigue load level of 0.3 , the COV of the maximum midspan deflection, the maximum tensile strain, and the residual tensile strain of rebar were $0.110,0.117$, and 0.181 , respectively. This indicates that as the fatigue load level increased, the plastic deformation of the specimen increased and the variation of the test results became larger.

Table 6 shows the variation of the ratio of residual strain to maximum strain of tensile rebar with the number of fatigue
TABLE 6: Ratio of residual strain to max strain.

\begin{tabular}{lcccc}
\hline \multirow{2}{*}{ Number } & \multicolumn{4}{c}{ Ratio of residual strain to maximum strain } \\
& 3 cycles & 1000 cycles & 20,000 cycles & 200,000 cycles \\
\hline A3 & 0.128 & 0.210 & 0.270 & 0.406 \\
A4 & 0.136 & 0.172 & 0.204 & 0.271 \\
A5 & 0.281 & 0.516 & 0.509 & 0.525 \\
A6 & 0.348 & 0.675 & 0.612 & 0.682 \\
B3 & 0.053 & 0.359 & 0.330 & 0.364 \\
B4 & 0.015 & 0.219 & 0.227 & 0.333 \\
B5 & 0.333 & 0.563 & 0.553 & 0.651 \\
B6 & 0.045 & 0.705 & 0.591 & 0.574 \\
B7 & 0.344 & 0.538 & 0.536 & 0.604 \\
C3 & 0.043 & 0.328 & 0.347 & 0.345 \\
C4 & 0.085 & 0.314 & 0.315 & 0.341 \\
C5 & 0.345 & 0.435 & 0.383 & 0.407 \\
C6 & 0.327 & 0.420 & 0.417 & 0.509 \\
\hline
\end{tabular}

load cycles. It is observed from the testing results that the ratio increased as the number of fatigue load cycles increased. Within the first 1000 cycles, the ratio showed a sharp rise. For the fatigue load level of 0.2 , the ratios of the residual strain to the maximum strain of tensile rebar were smaller than 0.40 after 200,000 fatigue loading cycles. For fatigue load level 0.3, the ratios were generally larger than 0.50 after 200,000 fatigue loading cycles.

3.3. Seawater Wet-Dry Cycles Test. The surface color of beam specimens of B series turned from light gray to pale yellow when increasing the number of wet-dry cycles. Specimens B3, B4, B5, B6, and B7 showed a significant phenomenon of selfhealing in seawater wet-dry cycles. It can be seen in Figure 10 that there were three fatigue cracks with the max width of $0.07 \mathrm{~mm}, 0.10 \mathrm{~mm}$, and $0.09 \mathrm{~mm}$ in beam specimen B5 before seawater dry-wet cycles. But after 100 cycles of seawater drywet only two cracks can be observed and the max width of the two cracks is $0.05 \mathrm{~mm}$. It might be caused by the selfrecovery performance of concrete. Şahmaran [16] reported that the deposit on the self-healing crack surface was calcite $\left(\mathrm{CaCO}_{3}\right)$ by $\mathrm{X}$-ray diffractogram and proved that concrete hydration was an exclusive cause of self-healing.

The number of observed fatigue cracks during the procedures of seawater wet-dry cycles is shown in Table 7. In this table, 0 cycles mean the number of seawater wet-dry cycles is 0 . It was observed that both the number of cracks and the maximum of the crack width were reduced when the number of wet-dry cycles increased. Most of the initial cracks disappeared after 100 cycles.

3.4. Alternating Actions of Freeze-Thaw and Seawater Immersion Test. The surface color of beam specimens of $\mathrm{C}$ series turned from light gray to taupe as the number of freeze-thaw cycles increased. In this series, cracks of beam specimens did not show an obvious self-healing. Some cracks even became wider and clearer after applying the freeze-thaw 


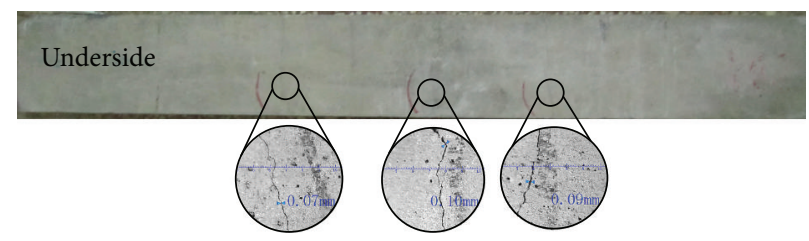

(a) B5 before seawater dry-wet cycles ( 0 cycles)

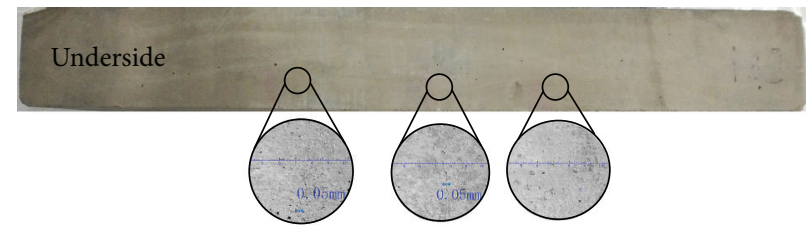

(b) B5 after 100 dry-wet cycles in seawater

FIGURE 10: Surface self-healing of B5 in seawater wet-dry process (16 times' magnification).

TABLE 7: Variation of fatigue cracks with different wet-dry cycles.

\begin{tabular}{lccccccccc}
\hline \multirow{2}{*}{ Number } & $\begin{array}{c}\text { Fatigue } \\
\text { load level }\end{array}$ & 0 cycles & 33 cycles & 66 cycles & 100 cycles & 0 cycles & 33 cycles & 66 cycles & 100 cycles \\
\hline B3 & 0.2 & 2 & 0 & 0 & 0 & 0.12 & 0 & 0 \\
B4 & 0.2 & 1 & 1 & 1 & 0 & 0.09 & 0.05 & 0.04 \\
B5 & 0.3 & 3 & 2 & 2 & 2 & 0.10 & 0.08 & 0.05 \\
B6 & 0.3 & 2 & 1 & 1 & 0 & 0.10 & 0.07 & 0.06 \\
B7 & 0.3 & 3 & 2 & 2 & 0 & 0.12 & 0.08 & 0.08 \\
\hline
\end{tabular}

cycles. It can be seen in Figure 11 that there were four fatigue cracks with the maximum width of $0.11 \mathrm{~mm}, 0.12 \mathrm{~mm}$, $0.09 \mathrm{~mm}$, and $0.09 \mathrm{~mm}$ in beam specimen C5 before freezethaw cycles. After 300 freeze-thaw cycles, there were still four fatigue cracks and the maximum width changed to $0.12 \mathrm{~mm}$, $0.10 \mathrm{~mm}, 0.07 \mathrm{~mm}$, and $0.10 \mathrm{~mm}$. The change of width is small, and it might be due to the fact that freeze-thaw cycles prevented the self-recovery of concrete.

The variation of fatigue cracks during the alternating freeze-thaw and seawater immersion test is shown in Table 8. In this table, 0 cycles mean the number of freeze-thaw cycles is 0 . It can be seen that the numbers of cracks remained unchanged and the maximum crack width became larger with increasing the number of cycles.

Comparisons between the beam specimens of series B and series $C$ revealed the following facts. The width of crack of specimens in series B (i.e., seawater wet-dry cycles) decreased gradually, and the width of cracks of specimens in series $\mathrm{C}$ (i.e., alternating freeze-thaw and seawater immersion) did not decrease; some even became larger.

3.5. Residual Strength Test of Beams. Beam specimens without fatigue loading were A1, A2, B1, B2, C1, and C2. In the static loading process, the first vertical cracks appeared in the midspan, and cracking load was $5.42 \mathrm{kN}, 5.65 \mathrm{kN}$, $5.64 \mathrm{kN}, 5.79 \mathrm{kN}, 4.71 \mathrm{kN}$, and $4.03 \mathrm{kN}$, respectively. With the increasing load cracks gradually developed, and the parallel cracks appeared. When cracks propagated to the location of the compression reinforcement, the tensile reinforcement yielded and the concrete compression zone crushed.
Another observation is that in the static loading process the original fatigue cracks of the test specimens further propagated, and new cracks appeared (Figure 12). Both the previous cracks (before applying the static load) and newly developed cracks (due to the static load) appeared in the vicinity of midspan. The specimen broke when cracks propagated to the location of the compression reinforcement, causing the yielding of tensile reinforcement and the crushing of the concrete compression zone along the fatigue cracks.

Figures 13-15 show the final fracture morphology of three series beam specimens. The fractures of FDRC beams were all along the fatigue cracks of the midspan.

Tables 9-11 show the residual capacity test results of the beams. The term $\delta_{y}$ is the midspan deflection when beam yielded, and the term $\delta_{u}$ is the midspan deflection at the ultimate load. The ductility factor is defined as the ratio of the ultimate deflection to the yield deflection. The yield modulus is the ratio of the yield load to the yield deflection.

Figures 16-18 show load-deflection curves of beams under different working environments. When fatigue loading level changed, each load-deflection curve had an approximate similar monotonic trend. For example, the yield load, ultimate load, and the stiffness of the beams decreased as the fatigue load level increased. However, due to the impact of different work environments, the stiffness varied differently.

It can be seen from Table 9 and Figure 16 that the yield load and ultimate load of specimens in A series decreased with the increasing fatigue load level, but the yield deflection and ultimate deflection were not significantly reduced. Muir and Bennett [6] and Award and Hilsdorf [7] revealed that 


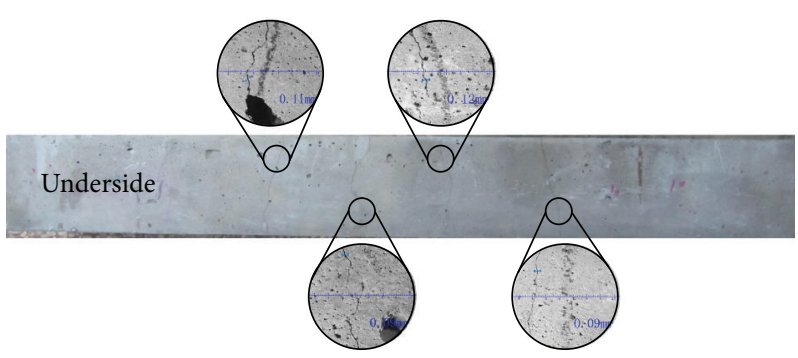

(a) C5 before freeze-thaw cycles

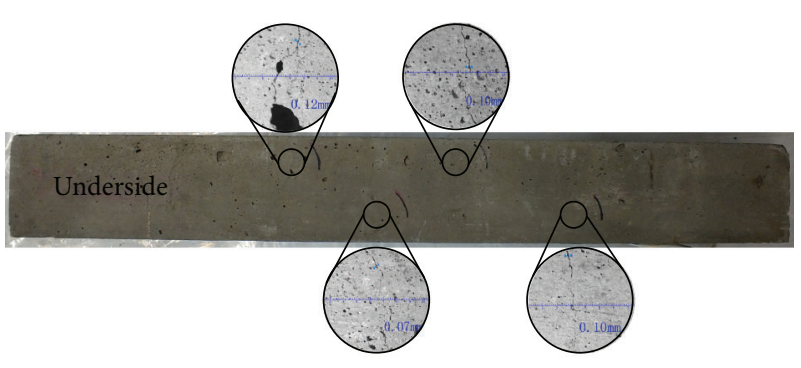

(b) C5 after 300 freeze-thaw cycles

FIGURE 11: Surface self-healing of C5 in freeze-thaw process (16 times' magnification).

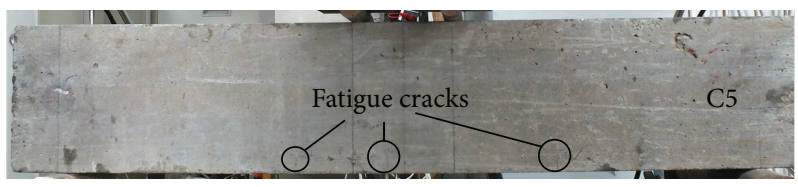

(a) C5 installed for testing

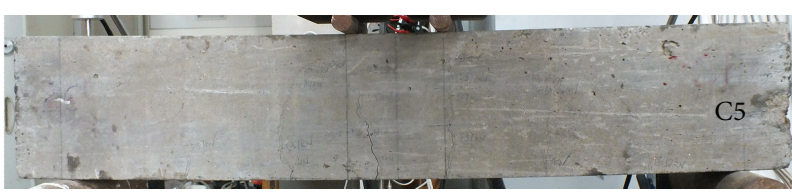

(b) C5 yielded

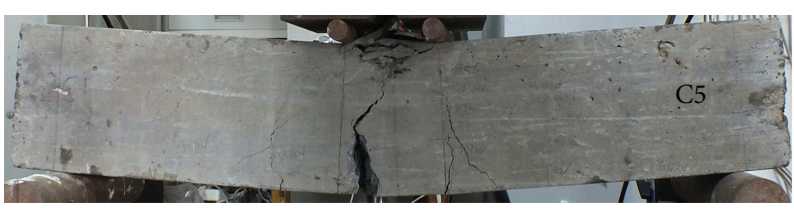

(c) C5 broken

FIGURE 12: Static loading process of beam specimen C5.

TABLE 8: Variation of fatigue cracks with different freeze-thaw cycles.

\begin{tabular}{|c|c|c|c|c|c|c|c|c|c|}
\hline \multirow{2}{*}{ Number } & \multirow{2}{*}{$\begin{array}{c}\text { Fatigue } \\
\text { load level }\end{array}$} & \multicolumn{4}{|c|}{ Number of cracks } & \multicolumn{4}{|c|}{ Max crack width/mm } \\
\hline & & 0 cycles & 100 cycles & 200 cycles & 300 cycles & 0 cycles & 100 cycles & 200 cycles & 300 cycles \\
\hline $\mathrm{C} 3$ & $0.1,0.2 P_{u}$ & 3 & 3 & 3 & 3 & 0.10 & 0.10 & 0.10 & 0.11 \\
\hline $\mathrm{C} 4$ & $0.1,0.2 P_{u}$ & 2 & 2 & 2 & 2 & 0.11 & 0.10 & 0.10 & 0.11 \\
\hline $\mathrm{C} 5$ & $0.1,0.3 P_{u}$ & 4 & 4 & 4 & 4 & 0.12 & 0.12 & 0.12 & 0.12 \\
\hline C6 & $0.1,0.3 P_{u}$ & 3 & 3 & 3 & 3 & 0.11 & 0.15 & 0.16 & 0.17 \\
\hline
\end{tabular}



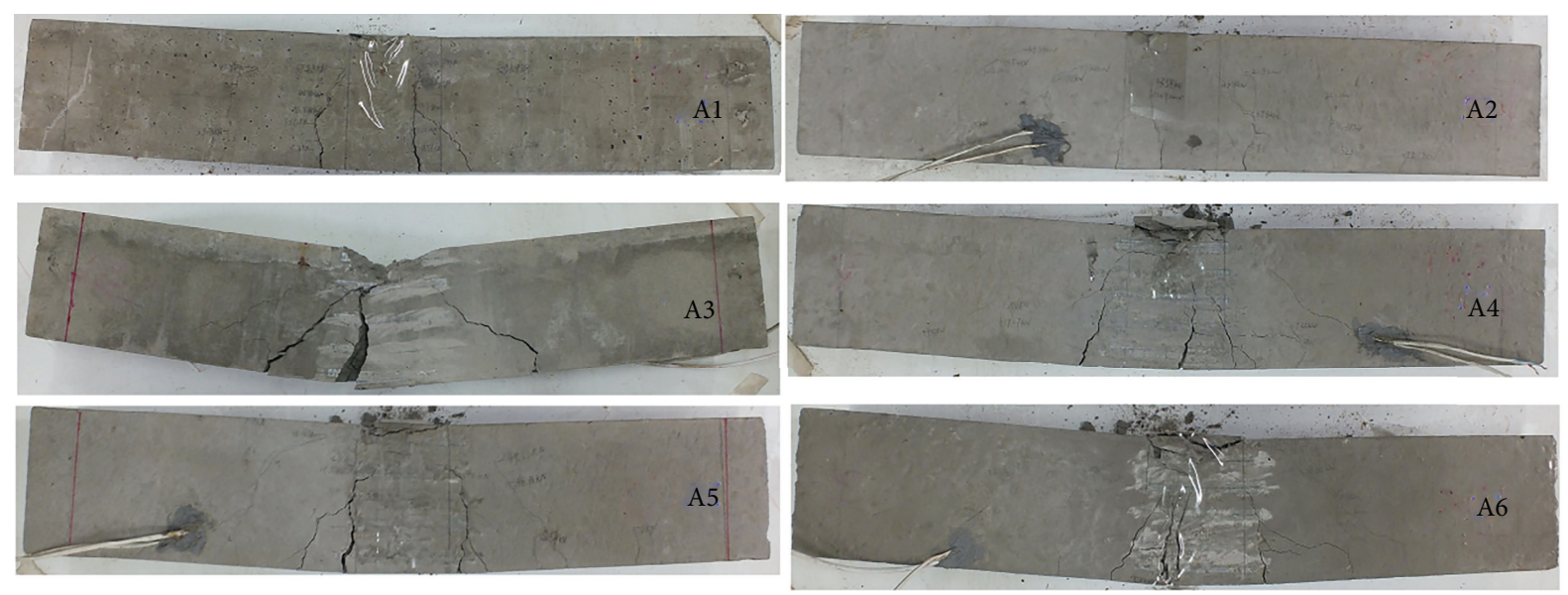

FIgURE 13: Testing results of beam specimens of A series.
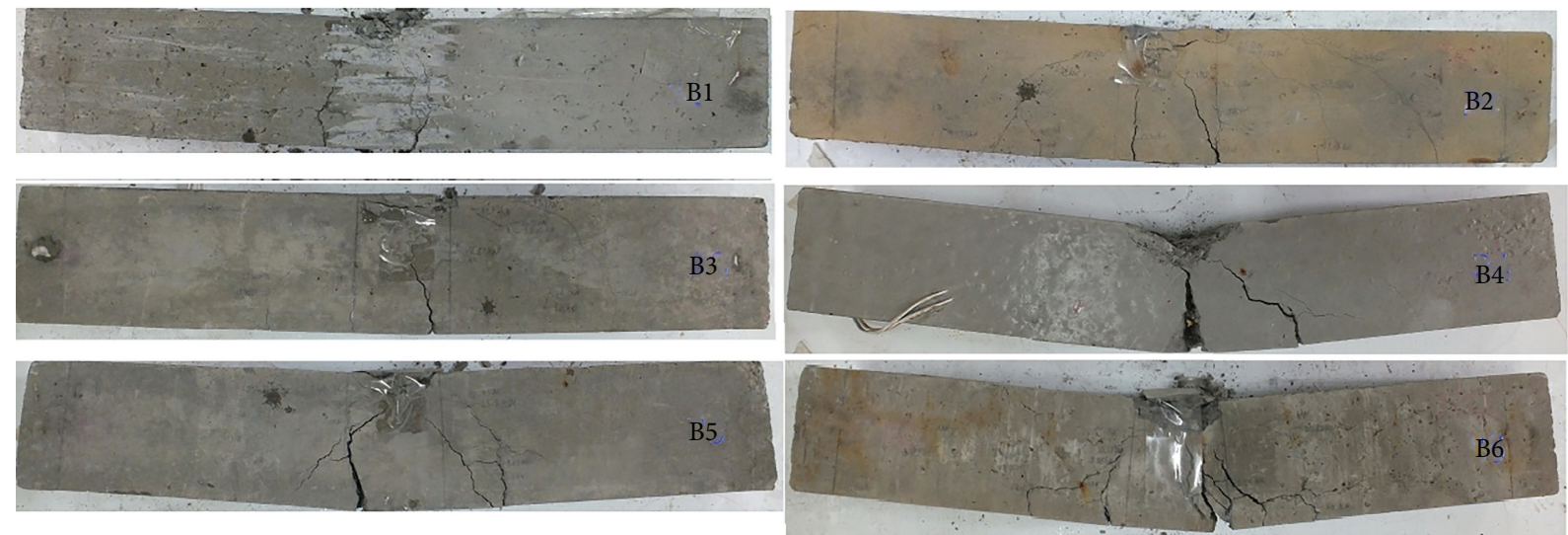

FIgURE 14: Testing results of beam specimens of B series.
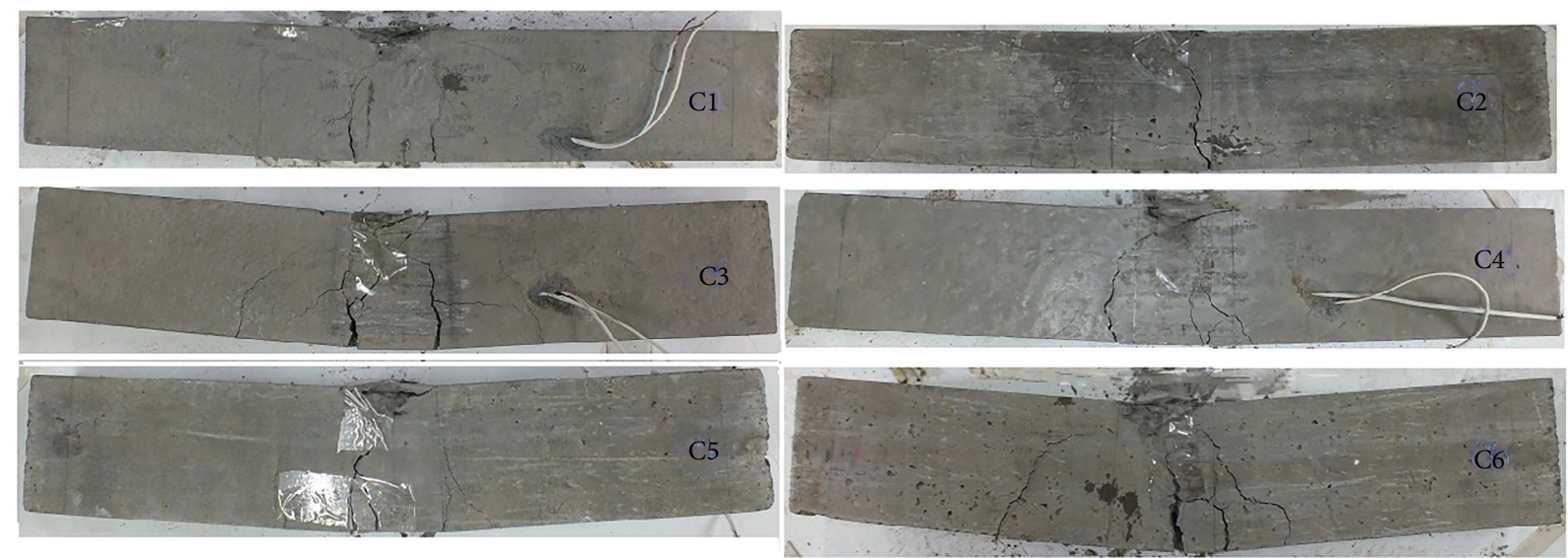

FIGURE 15: Testing results of beam specimens of $\mathrm{C}$ series. 
TABLE 9: Residual capacity results of beams of A series.

\begin{tabular}{|c|c|c|c|c|c|c|c|}
\hline Number & $\begin{array}{c}\text { Fatigue } \\
\text { load level }\end{array}$ & $\begin{array}{c}\text { Yield load } \\
\mathrm{kN}\end{array}$ & $\delta_{y} / \mathrm{mm}$ & $\begin{array}{c}\text { Ultimate load } \\
\mathrm{kN}\end{array}$ & $\delta_{u} / \mathrm{mm}$ & Ductility factor & $\begin{array}{c}\text { Yield modulus } \\
\mathrm{kN} / \mathrm{mm}\end{array}$ \\
\hline$\overline{\mathrm{A} 1}$ & 0 & 51.80 & 2.59 & 64.29 & 5.68 & 3.58 & 20.00 \\
\hline $\mathrm{A} 2$ & 0 & 54.21 & 2.57 & 65.87 & 5.28 & 2.73 & 21.13 \\
\hline A3 & 0.2 & 50.28 & 2.28 & 62.98 & 4.27 & 5.61 & 22.07 \\
\hline $\mathrm{A} 4$ & 0.2 & 46.40 & 2.24 & 58.69 & 5.28 & 6.24 & 20.69 \\
\hline A5 & 0.3 & 46.18 & 2.69 & 54.72 & 5.27 & 5.21 & 17.18 \\
\hline A6 & 0.3 & 45.54 & 2.53 & 52.28 & 4.17 & 5.53 & 17.98 \\
\hline
\end{tabular}

TABLE 10: Residual capacity results of beams of B series.

\begin{tabular}{lccccccc}
\hline Number & $\begin{array}{c}\text { Fatigue } \\
\text { load level }\end{array}$ & $\begin{array}{c}\text { Yield load } \\
\mathrm{kN}\end{array}$ & $\delta_{y} / \mathrm{mm}$ & $\begin{array}{c}\text { Ultimate load } \\
\mathrm{kN}\end{array}$ & $\delta_{u} / \mathrm{mm}$ & Ductility factor & $\begin{array}{c}\text { Yield modulus } \\
\mathrm{kN} / \mathrm{mm}\end{array}$ \\
\hline B1 & 0 & 52.12 & 2.67 & 62.05 & 5.27 & 6.34 & 19.52 \\
B2 & 0 & 49.81 & 2.58 & 58.5 & 4.89 & 5.24 & 19.31 \\
B3 & 0.2 & 43.39 & 2.42 & 53.44 & 5.43 & 5.87 & 5.69 \\
B4 & 0.2 & 45.25 & 2.20 & 58.1 & 5.38 & 5.61 & 17.95 \\
B5 & 0.3 & 39.66 & 2.50 & 51.74 & 6.88 & 5.61 & 15.89 \\
B6 & 0.3 & 40.75 & 2.49 & 48.71 & 4.54 & 16.34 \\
\hline
\end{tabular}

TABLE 11: Residual capacity test results of C series.

\begin{tabular}{|c|c|c|c|c|c|c|c|}
\hline Number & $\begin{array}{c}\text { Fatigue } \\
\text { load level }\end{array}$ & $\begin{array}{l}\text { Yield load } \\
\mathrm{kN}\end{array}$ & $\delta_{y} / \mathrm{mm}$ & $\begin{array}{l}\text { Ultimate load } \\
\text { kN }\end{array}$ & $\delta_{u} / \mathrm{mm}$ & Ductility factor & $\begin{array}{c}\text { Yield modulus } \\
\mathrm{kN} / \mathrm{mm}\end{array}$ \\
\hline $\mathrm{Cl}$ & 0 & 49.10 & 2.73 & 56.2 & 3.90 & 4.38 & 17.98 \\
\hline $\mathrm{C} 2$ & 0 & 46.37 & 2.53 & 55.27 & 4.94 & 3.24 & 18.32 \\
\hline $\mathrm{C} 3$ & 0.2 & 43.82 & 2.78 & 51.47 & 5.57 & 3.11 & 15.78 \\
\hline $\mathrm{C} 4$ & 0.2 & 45.41 & 2.86 & 53.41 & 4.56 & 5.46 & 15.88 \\
\hline $\mathrm{C} 5$ & 0.3 & 41.17 & 2.65 & 49.28 & 6.19 & 5.28 & 15.53 \\
\hline C6 & 0.3 & 40.10 & 2.68 & 45.97 & 4.80 & 5.22 & 14.96 \\
\hline
\end{tabular}

residual compressive strength of concrete did not reduce in the early stage of fatigue loading. It can be inferred that the decrease of flexural capacity of A series beams was mainly caused by the degradation of residual strength of reinforcement bars and bending stiffness of RC beams. Compared with beams A1 and A2 (without fatigue loading), the yield load of beams A3 and A4 (fatigue load level 0.2) decreased, which indicated that the elastic stage was shortened due to the loading. The yield moduli of beams A5 and A6 (fatigue load level 0.3) decreased significantly, indicating that the stiffness of the beam was weakened due to fatigue loading.

It can be seen from Table 10 and Figure 17 that the yield load and ultimate load of beam specimens in B series decreased with the increasing fatigue load level. The yield moduli of specimens B5 and B6 (fatigue load level 0.3) decreased significantly, indicating the reduction of the stiffness due to the fatigue loading.

It can be seen from Table 11 and Figure 18 that the yield load and ultimate load of specimens in C series decrease with an increasing fatigue load level, but the yield deflections and ultimate deflections do not decrease significantly.
Based on the results shown in Tables 9-11, the yield strength, ultimate strength, and yield moduli of the specimens without fatigue loading decreased significantly due to the alternating freeze-thaw and seawater immersion; however, those quantities were not affected too much by seawater wet-dry cycles. For specimens at the same fatigue loading level, the yield strength, yield modulus, and ultimate strength of $\mathrm{C}$ series are the smallest ones among the three series. The values of the three variables in B series are smaller than those of A series.

Figures 19-21 present load-deflection curves of the beams at the same fatigue load level but in different environment conditions. It can be seen from Figures 19-21 that the ultimate strength of B series beams was smaller than that of the A series beams, and the ultimate strength of $C$ series beams was smaller than that of the $B$ series beams. Based on the results in Figures 19-21, it can be concluded that the yield strength and ultimate strength of beams were reduced due to the action of the seawater wet-dry cycle or alternating freeze-thaw and seawater immersion. For FDRC beams at the fatigue load level of 0.2 , the action of seawater wet-dry 


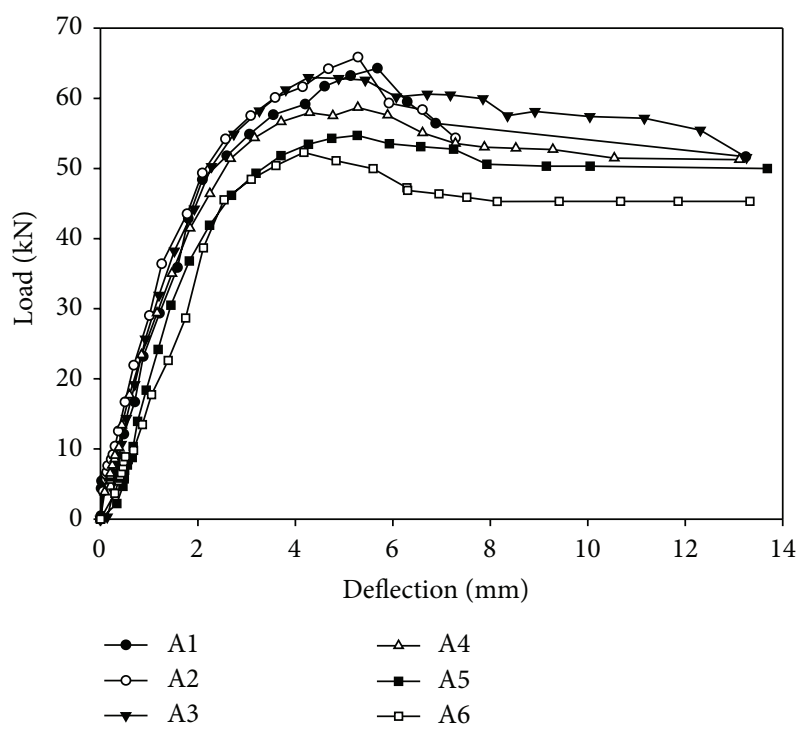

FIgURE 16: Load-deflection curves of A series.

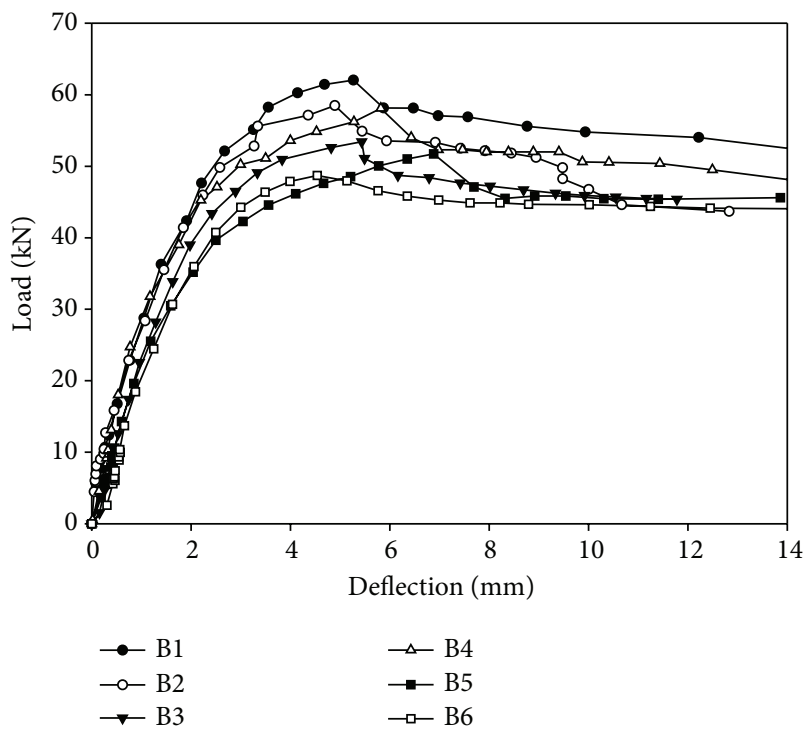

FIgURE 17: Load-deflection curves of B series.

cycles and alternating freeze-thaw and seawater immersion not only reduced the yield strength and ultimate strength, but also affected the elastic stiffness. The alternating freeze-thaw and seawater immersion had a more severe impact on the deterioration of the mechanical behavior of beam specimens. For FDRC beams at the fatigue load level of 0.3 , although the environment conditions affected the yield strength, ultimate strength, and the elastic stiffness, the contribution of wet-dry cycles and freeze-thaw cycles was less than that introduced by the increment of fatigue amplitude.

Figure 22 shows the load-bending stiffness curves of the beam specimens. The curves describe the variation of bending stiffness of the beam specimens in the static loading process. The bending stiffness (BS) is defined as the ratio of flexural moment to the curvature at midspan during

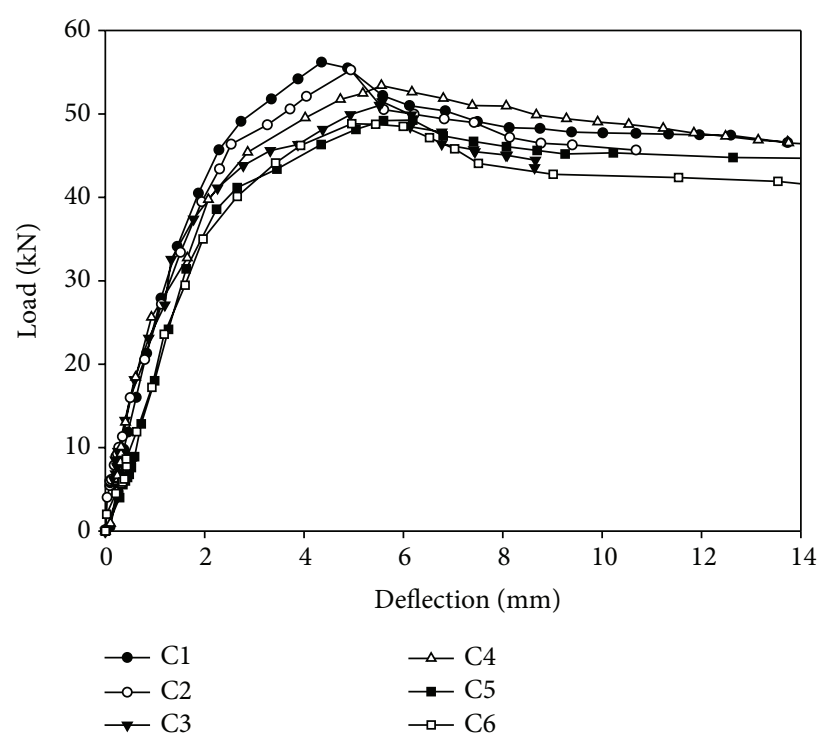

Figure 18: Load-deflection curves of C series.

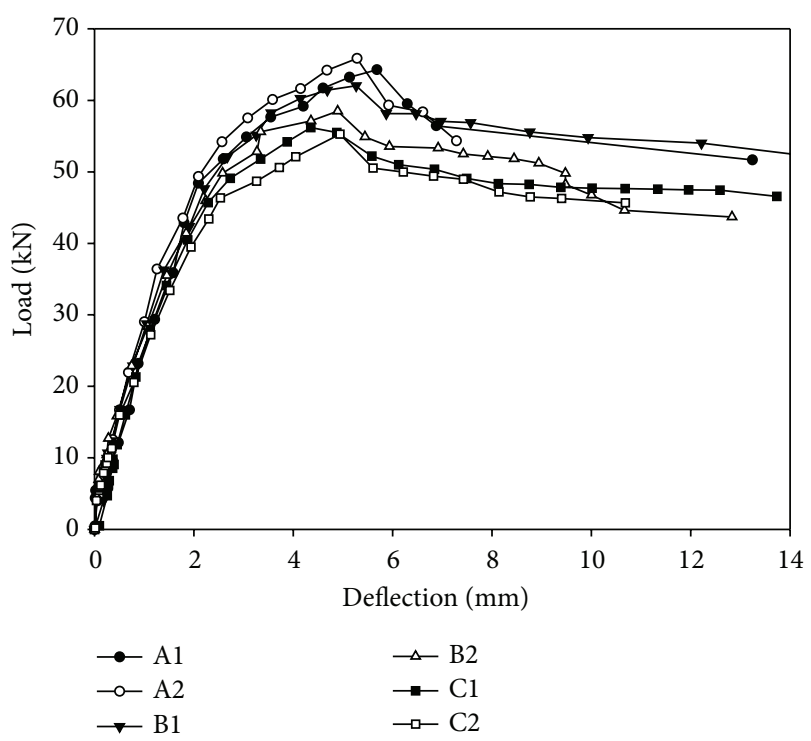

FIGURE 19: Load-deflection curves in different environments.

static loading. As shown in Figure 22, BS of A series beams decreased significantly with the increasing of the fatigue load level. BS of case A6 was very small because of the discreteness of initial stiffness and concrete fatigue damage of RC beams. BS of B series beams was close when the load was less than $32 \mathrm{kN}$ and had larger difference when the load became larger. This showed that the seawater wet-dry cycles reduced BS of beams, and the reduction of BS of beams magnified the deterioration effect of fatigue damage when the load was larger than $32 \mathrm{kN}$. BS of C series beams was almost identical in all static loading procedures. This showed that the alternating freeze-thaw and seawater immersion decreased the BS of beams regardless of the fact that the beams had been fatiguedamaged or not. 


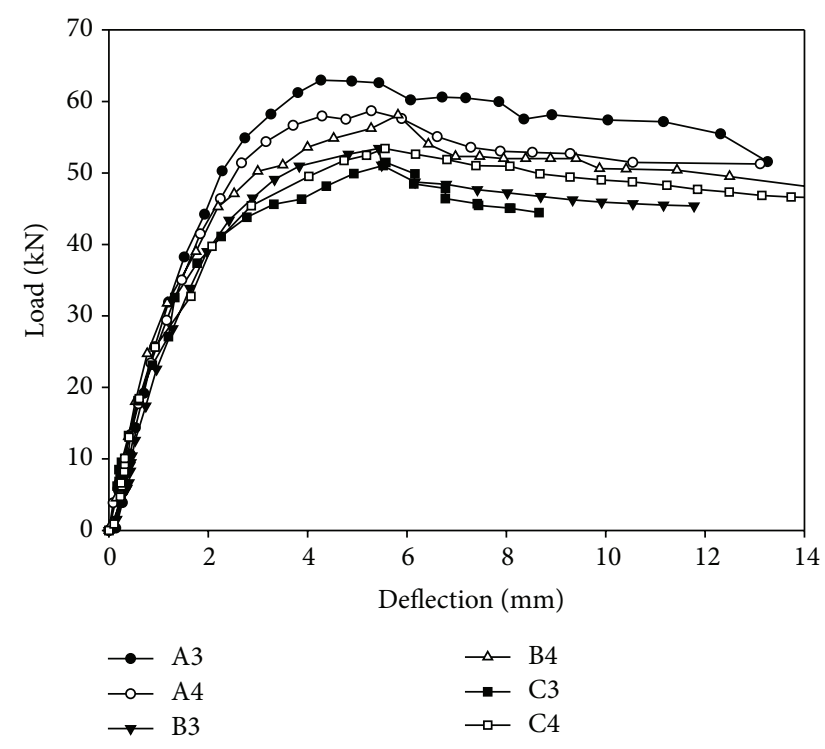

FIGURE 20: Load-deflection curves at load level 0.2.

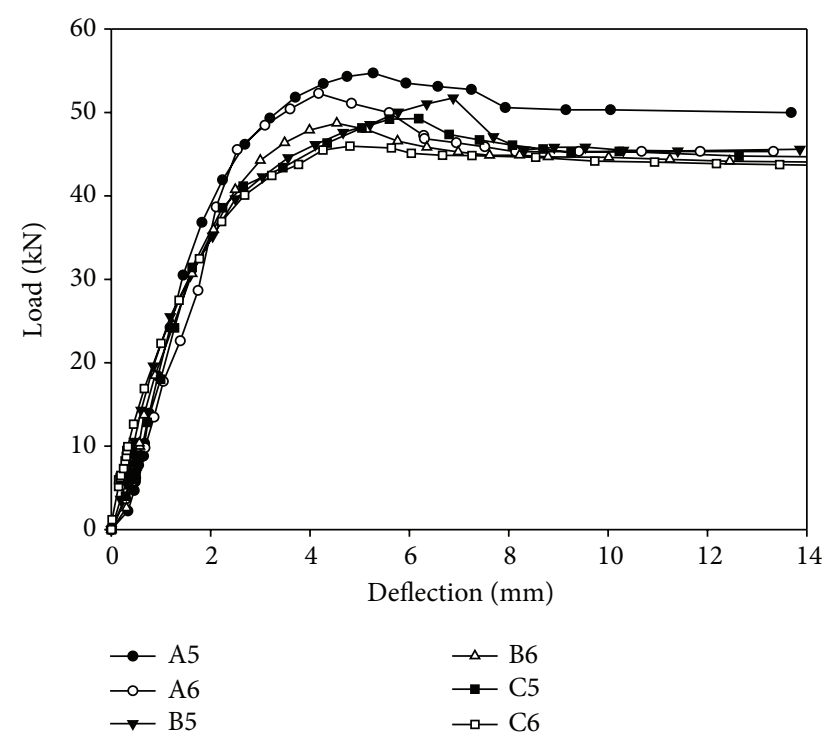

FIGURE 21: Load-deflection curves at load level 0.3.

Comparing curves with the same fatigue load level in Figure 22, it can be seen that the seawater wet-dry cycles and alternating freeze-thaw and seawater immersion decreased BS of beams significantly. The specific results are in Table 12.

Table 13 shows results of residual capacity test for beams in different erosional environments after fatigue testing at different fatigue load levels. The 3rd column shows the average yield load of each group and the 4th column shows the reduction of beam specimens of each group with respect to the average yield load of specimens A1 and A2. The 5th column is the average yield modulus of each group, and the 6 th column is the reduction of each group with respect to the average yield modulus of specimens A1 and A2. The 7th column is the average ultimate load of each group, and the 8th column is the reduction of each group with respect to the average ultimate load of specimens A1 and A2.

It can be seen from the 3 th and 4 th columns in Table 13 that the yield strength of beam specimens decreased as the fatigue load level increased under the same working environment. Compared with the yield strength obtained in the air, the seawater wet-dry cycles and alternating freezethaw and seawater immersion cycles can both increase the amount of reduction in yield strength of the FDRC beams. For beams without fatigue damage, seawater wet-dry cycles had a very small effect on the yield strength, but alternating freeze-thaw and seawater immersion decreased the yield strength significantly. This is consistent with the results of the concrete cube test. In the concrete cube test it was shown that under the same conditions of reinforcement the yield strength of beams depends on the strength of the concrete.

It can be seen from the 5th and 6th columns in Table 13 that the yield moduli of beam specimens had a small change in the air environment when the fatigue load level was low, but when the fatigue load level increased to 0.3 , the yield moduli of specimens decreased significantly. Seawater wet-dry cycles and alternating freeze-thaw and seawater immersion cycles both increased the reduction of yield moduli of beams fatigue damage, and the yield moduli of specimens had a significant reduction when the fatigue load level was small. Without fatigue damage, the yield moduli of specimens in all three working environments were close. With fatigue damage, the yield moduli of $B$ series of beams were smaller than those of the A series of beams. The $\mathrm{C}$ series of beams had smaller yield moduli than that of the $\mathrm{B}$ series of beams.

The data in the 7 th and 8 th columns of Table 13 show that the ultimate strength of beam specimens decreased as the fatigue load level increased in the same working environment. Compared with the ultimate strength obtained from specimens in the air (A series), seawater wet-dry cycles (B series) and alternating freeze-thaw and seawater immersion cycles ( $\mathrm{C}$ series) both increased the amount of reduction in ultimate strength of FDRC beams. The ultimate strengths of beam specimens of $B$ series were lower than those of A series, and those of $\mathrm{C}$ series were lower than $\mathrm{B}$ series.

Figure 23 shows the average variation of yield strength and ultimate strength of each series of beam specimens at different fatigue load levels. It can be seen that the yield strength of A series and B series decreased linearly as the fatigue load level increased. The ultimate strength of three series all decreased with an approximately similar speed as the fatigue load level increased. When the fatigue load was 0 , the amount of reduction for $\mathrm{C}$ series with respect to $\mathrm{A}$ series was about 2 times of that for $B$ series with respect to A series. While fatigue load level was 0.2 , this quantity was about 1.6. When the fatigue load level was no more than 0.2 , the amount of reduction of $\mathrm{C}$ series with respect to $\mathrm{A}$ series and the amount of reduction of $\mathrm{B}$ series with respect to A series remained the same. The amount of reduction for $B$ series with respect to the A series decreased. When the fatigue load level was 0.3 , the ultimate strengths of the $\mathrm{B}$ and $\mathrm{C}$ series simultaneously reduced comparing with the ultimate strength of the A series. It was the fatigue damage that contributes significantly to the deterioration of flexural performance. 


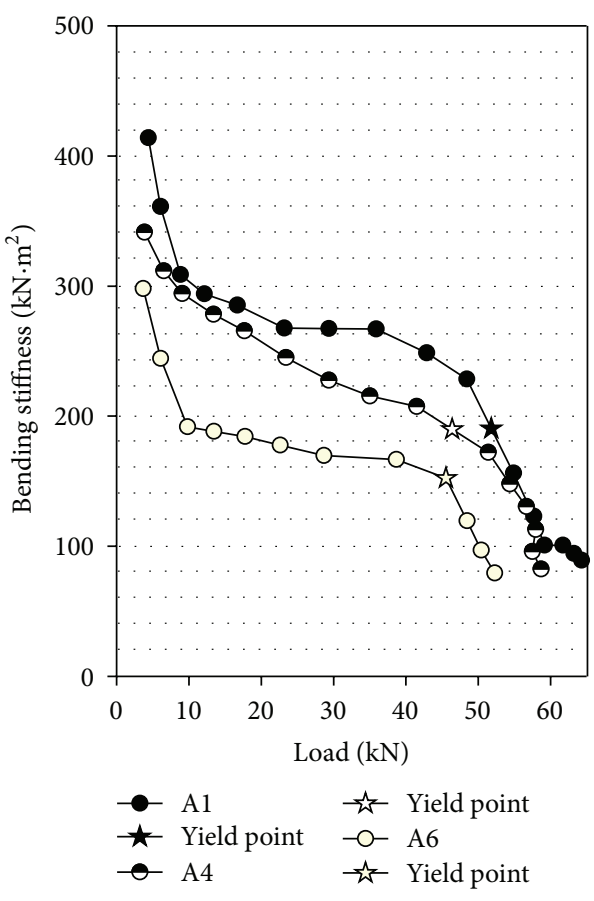

(a) Air

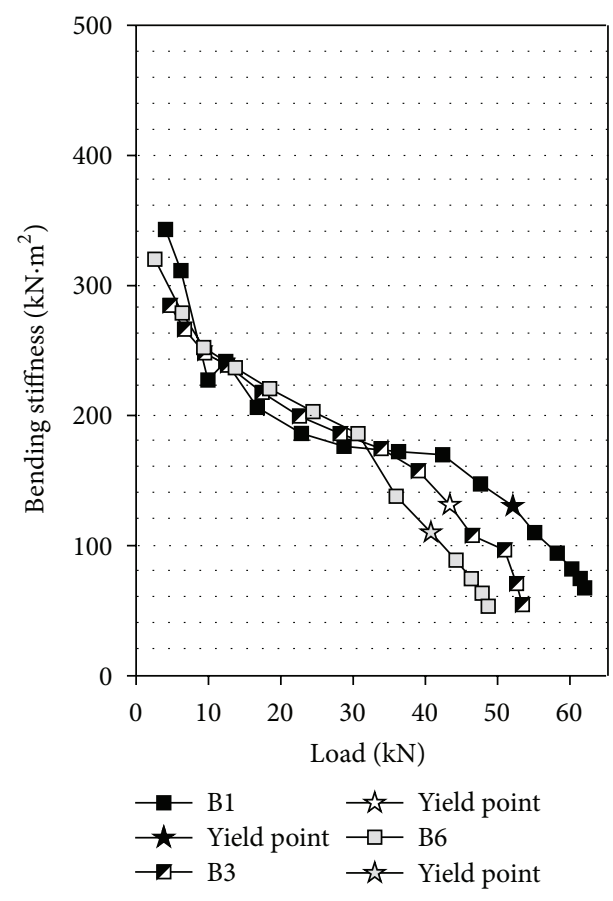

(b) Wet-dry cycles

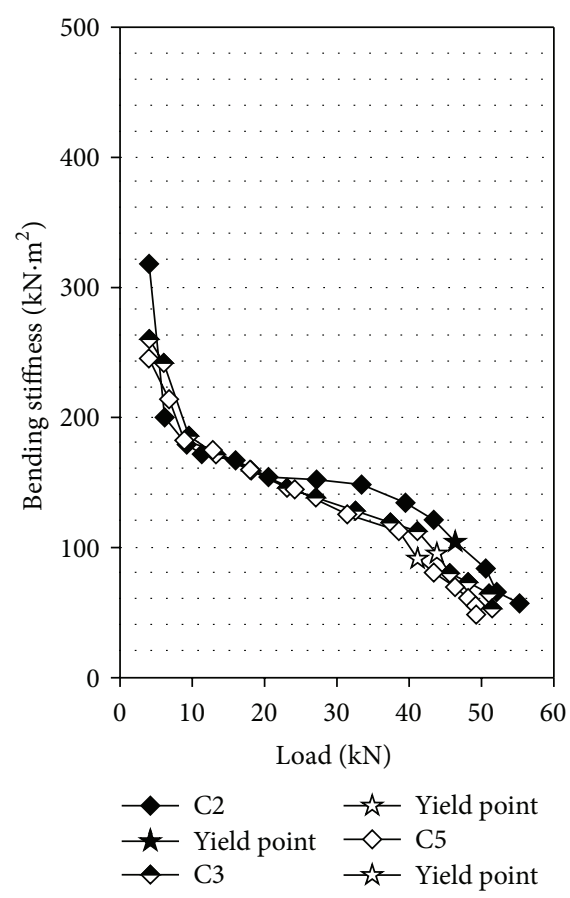

(c) Freeze-thaw cycles

Figure 22: Load-bending stiffness curves of the beams.

Figure 24 shows that the yield moduli of beam specimens vary with the fatigue load level. It is shown that the yield moduli of A series and B series did not decrease when the fatigue load level was less than 0.2 , but the yield moduli decreased rapidly at the load level of 0.3 . This means that low fatigue load level (no more than 0.2) cannot decrease the yield modulus of RC beam under air environment and seawater wet-dry cycling environment. Because of the discreteness of yield moduli, the yield moduli of the beams of A series and $\mathrm{B}$ series at the fatigue load level of 0.2 were larger than that 
TABLE 12: Bending stiffness analysis.

\begin{tabular}{|c|c|c|c|c|c|c|c|}
\hline $\begin{array}{l}\text { Fatigue } \\
\text { load level }\end{array}$ & Specimen & $\begin{array}{c}\text { Initial stiffness } \\
\mathrm{kN} \cdot \mathrm{m}^{2}\end{array}$ & amplitude reduction & $\begin{array}{c}\text { Yield stiffness } \\
\mathrm{kN} \cdot \mathrm{m}^{2}\end{array}$ & amplitude reduction & $\begin{array}{l}\text { Ultimate stiffness } \\
\qquad \mathrm{kN} \cdot \mathrm{m}^{2}\end{array}$ & amplitude reduction \\
\hline \multirow{3}{*}{0} & $\mathrm{~A} 1$ & 414 & 0 & 190 & 0 & 89 & 0 \\
\hline & B1 & 343 & $17.1 \%$ & 130 & $31.6 \%$ & 68 & $23.6 \%$ \\
\hline & $\mathrm{C} 2$ & 318 & $23.2 \%$ & 104 & $45.3 \%$ & 57 & $36.0 \%$ \\
\hline \multirow{3}{*}{0.2} & A4 & 341 & 0 & 190 & 0 & 82 & 0 \\
\hline & B3 & 324 & $5.0 \%$ & 131 & $31.1 \%$ & 55 & $32.9 \%$ \\
\hline & $\mathrm{C} 3$ & 260 & $23.7 \%$ & 95 & $50.0 \%$ & 53 & $35.4 \%$ \\
\hline \multirow{3}{*}{0.3} & A6 & 298 & 0 & 152 & 0 & 79 & 0 \\
\hline & B6 & 320 & $-7.4 \%$ & 110 & $27.6 \%$ & 53 & $32.9 \%$ \\
\hline & C5 & 245 & $17.8 \%$ & 91 & $40.1 \%$ & 48 & $39.2 \%$ \\
\hline
\end{tabular}

TABLE 13: Residual capacity results analysis.

\begin{tabular}{|c|c|c|c|c|c|c|c|}
\hline Number & $\begin{array}{c}\text { Fatigue } \\
\text { load level }\end{array}$ & $\begin{array}{c}\text { Yield strength } \\
\mathrm{kN}\end{array}$ & $\begin{array}{c}\text { Reduction } \\
\%\end{array}$ & $\begin{array}{c}\text { Yield modulus } \\
\mathrm{kN} / \mathrm{mm}\end{array}$ & $\begin{array}{c}\text { Reduction } \\
\%\end{array}$ & $\begin{array}{l}\text { Ultimate strength } \\
\mathrm{kN}\end{array}$ & $\begin{array}{c}\text { Reduction } \\
\%\end{array}$ \\
\hline $\mathrm{A} 1, \mathrm{~A} 2$ & 0 & 53.01 & 0 & 20.57 & 0 & 65.08 & 0 \\
\hline $\mathrm{A} 3, \mathrm{~A} 4$ & 0.2 & 48.34 & $8.8 \%$ & 21.38 & $-3.8 \%$ & 60.84 & $6.5 \%$ \\
\hline A5, A6 & 0.3 & 45.86 & $13.5 \%$ & 17.58 & $17.0 \%$ & 53.5 & $17.8 \%$ \\
\hline $\mathrm{B} 1, \mathrm{~B} 2$ & 0 & 50.97 & $3.8 \%$ & 19.42 & $5.6 \%$ & 60.28 & $7.4 \%$ \\
\hline $\mathrm{B} 3, \mathrm{~B} 4$ & 0.2 & 44.32 & $16.4 \%$ & 19.29 & $6.6 \%$ & 55.77 & $14.3 \%$ \\
\hline B5, B6 & 0.3 & 40.21 & $24.1 \%$ & 16.12 & $27.6 \%$ & 50.23 & $22.8 \%$ \\
\hline $\mathrm{C} 1, \mathrm{C} 2$ & 0 & 47.74 & $9.95 \%$ & 18.15 & $11.8 \%$ & 55.74 & $14.4 \%$ \\
\hline C3, C4 & 0.2 & 44.62 & $15.8 \%$ & 15.83 & $23.0 \%$ & 52.44 & $19.4 \%$ \\
\hline C5, C6 & 0.3 & 40.64 & $23.3 \%$ & 15.25 & $34.9 \%$ & 47.63 & $26.8 \%$ \\
\hline
\end{tabular}

at the fatigue load level of 0.0 . The yield moduli of $\mathrm{C}$ series beam specimens decreased linearly as the fatigue load level increased.

\section{Conclusion}

(1) The residual bending capacity of FDRC beams in the air reduces as the fatigue load level increases. The reduction of bearing capacity is mainly due to the reduction of yield strength of the reinforcement bars, and the decrease of bending stiffness is caused by fatigue damage accumulation.

(2) The residual yield load and ultimate load of the beams without fatigue damage can be decreased by the seawater wet-dry cycles and the alternating freeze-thaw and seawater immersion cycles. This is mainly due to the decrease of the concrete compressive strength.

(3) The residual yielding strength and ultimate strength of FDRC beams under the environment of seawater wetdry cycles reduce as the fatigue load level increases. The residual yielding strength and ultimate strength of FDRC beams under the environment of alternating freeze-thaw and seawater immersion cycles reduce as the fatigue load level increases. Contributions from the three factors to the reduction, from smaller to larger, are air, seawater wetdry, and alternating freeze-thaw and seawater immersion, respectively.

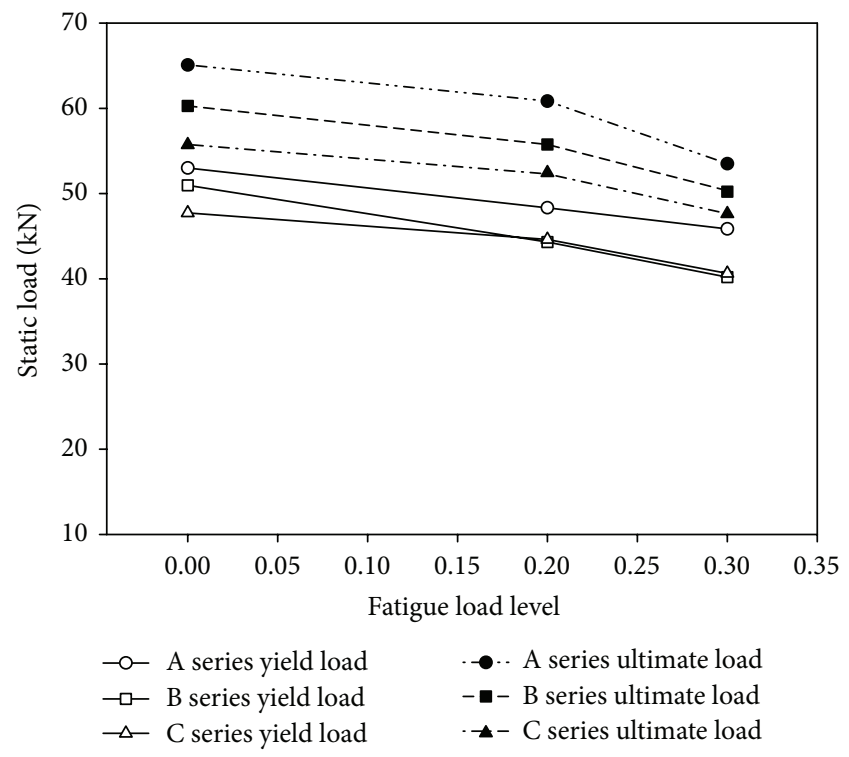

Figure 23: Yield load and ultimate load with fatigue load level.

(4) The fatigue cracks of beams exhibit self-healing in the environment of seawater wet-dry cycles; however, the self-healing is not obvious in the environment of alternating freeze-thaw and seawater immersion cycles. 


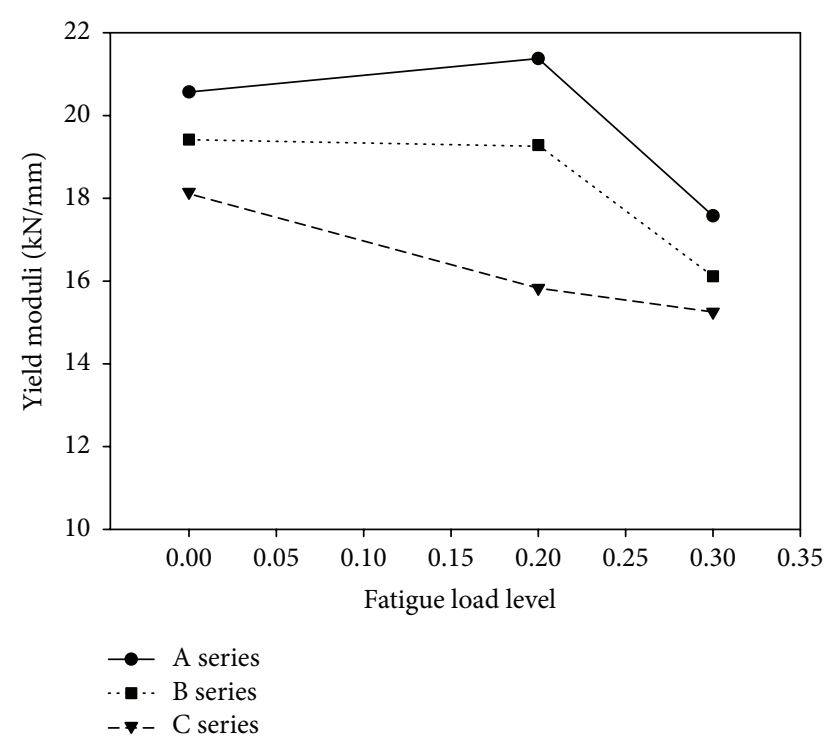

Figure 24: Yield modulus with fatigue load level.

200,000 cycles of fatigue loading at small fatigue load levels, for example, 0.2 and 0.3 in this study, can introduce serious deteriorations of mechanical behavior of RC beams due to the synthetic actions of fatigue damage and erosion environment and can jeopardize the structural integrity. The quantitative modeling of combined effect to FDRC structures will be investigated in the future.

\section{Conflict of Interests}

The authors declare that there is no conflict of interests regarding the publication of this paper.

\section{Acknowledgments}

This work was financially supported by the National Science Foundation of China (Grants nos. 51108015 and 51178020) and the Open Project of State Key Laboratory of Subtropical Building Science, South China University of Technology (no. 2012KA03).

\section{References}

[1] N. Feng, J. Cai, Q. Niu, and S. Zhang, "Study of the deterioration and its countermeasures of Shandong coastal highway reinforced concrete bridge," in Proceedings of the Durability and Durability Design of Concrete Structures, pp. 141-147, Tsinghua University, Beijing, China, 2002, (Chinese).

[2] T. S. Chang and C. E. Kesler, "Fatigue behavior of reinforced concrete beams," ACI Journal Proceedings, vol. 55, no. 8, pp. 245254, 1958.

[3] F. S. Ople and C. L. Hulsbos, "Probable fatigue life of plain concrete with stress gradient," ACI Journal, Proceedings, vol. 63, no. 1, pp. 59-82, 1966.

[4] R. Tepfer, J. Gørlin, and T. Samuelsson, "Concrete subjected to pulsating load and pulsating deformation of different pulse waveforms," Nordisk Betongstämpling, no. 4, pp. 27-36, 1973.
[5] M. Schläfli and E. Brühwiler, "Fatigue of existing reinforced concrete bridge deck slabs," Engineering Structures, vol. 20, no. 11, pp. 991-998, 1998.

[6] S. E. Muir and E. W. Bennett, "Some fatigue tests of highstrength concrete in axial compression," Magazine of Concrete Research, vol. 19, no. 59, pp. 113-117, 1967.

[7] M. E. Award and H. K. Hilsdorf, "Strength and deformation characteristics of plain concrete subjected to high repeated and sustained load," in Proceedings of the Abeles Symposium of Fatigue on Concrete, SP-41-1, pp. 1-13, ACI Publication, 1974.

[8] R. Talreja and W. Weibull, "Probability of fatigue failure based on residual strength," Fracture, vol. 2, pp. 19-24, 1977.

[9] S. Ling and Z. Li, "Study on the distribution rule of fatigue residual strength," in Proceedings of the ICF International Symposium on Fracture Mechanics, pp. 724-729, Science Press, Beijing, China, 1984.

[10] J. L. Bannister, "Fatigue and corrosion fatigue of torbar reinforcement," The Structural Engineer, vol. 56, no. 3, pp. 77-85, 1978.

[11] T. A. Radian, Effect of corrosion, freeze-thaw cycles and their combined effects on the fatigue behavior of reinforced concrete [M.S. thesis], University of Rhode Island, Kingston, RI, USA, 1989.

[12] R. Al-Hammoud, K. Soudki, and T. H. Topper, "Bond analysis of corroded reinforced concrete beams under monotonic and fatigue loads," Cement \& Concrete Composites, vol. 32, no. 3, pp. 194-203, 2010.

[13] H. Wang and J. Gong, "Experimental study on corrosion fatigue of RC beams," Journal of Building Structures, vol. 25, no. 5, pp. 105-110, 2004 (Chinese).

[14] J. Yuan, Y. Liu, H. Li, and B. Zhang, "Experimental investigation of the variation of concrete pores under the action of freezethaw cycles by using X-ray CT," Advances in Materials Science and Engineering, vol. 2014, Article ID 571357, 11 pages, 2014.

[15] B. Diao, J. Zhang, Y. Ye, and S. Cheng, "Effects of freeze-thaw cycles and seawater corrosion on the behavior of reinforced airentrained concrete beams with persistent loads," Journal of Cold Regions Engineering, vol. 27, no. 1, pp. 44-53, 2013.

[16] M. Şahmaran, "Effect of flexure induced transverse crack and self-healing on chloride diffusivity of reinforced mortar," Journal of Materials Science, vol. 42, no. 22, pp. 9131-9136, 2007. 

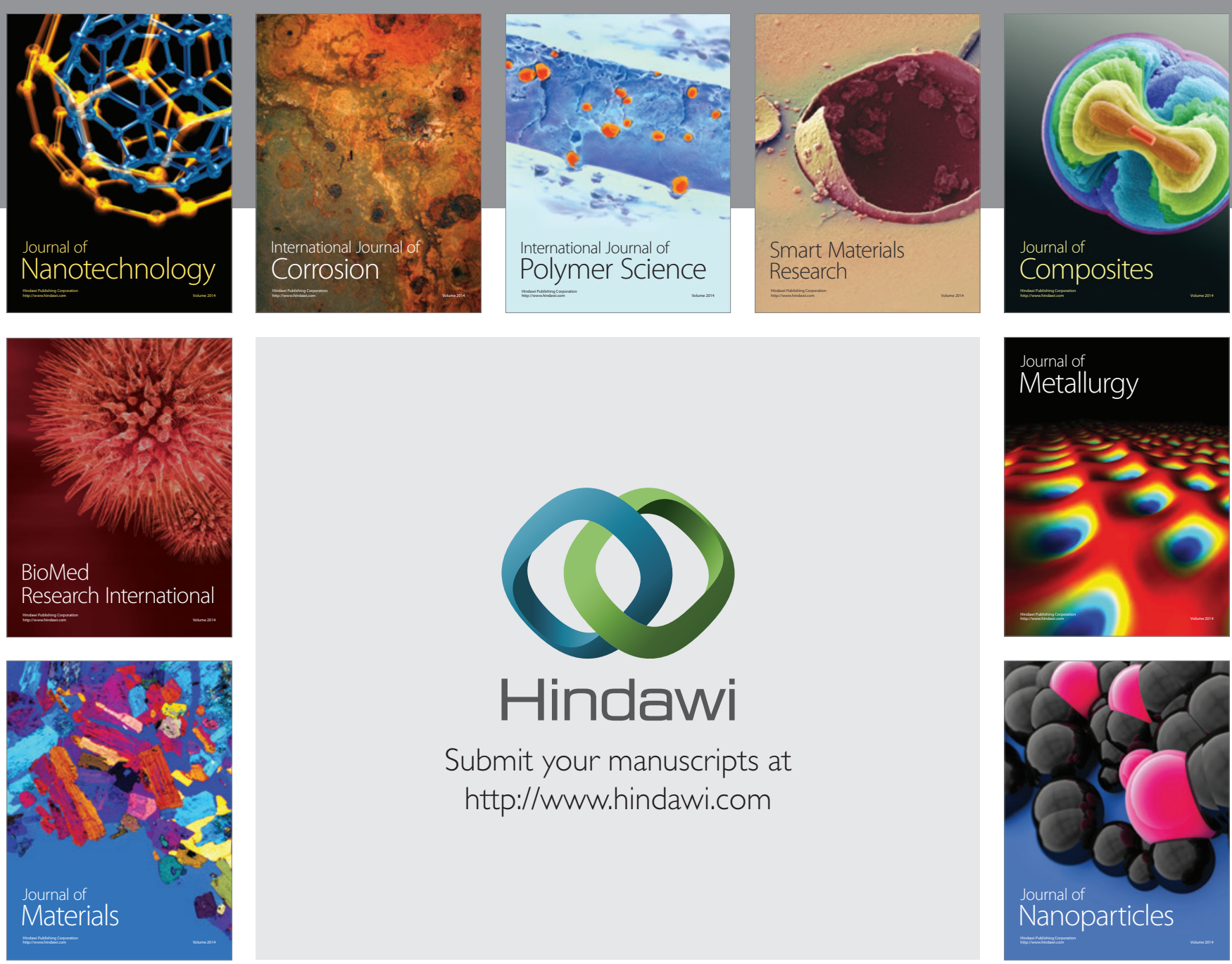

Submit your manuscripts at http://www.hindawi.com
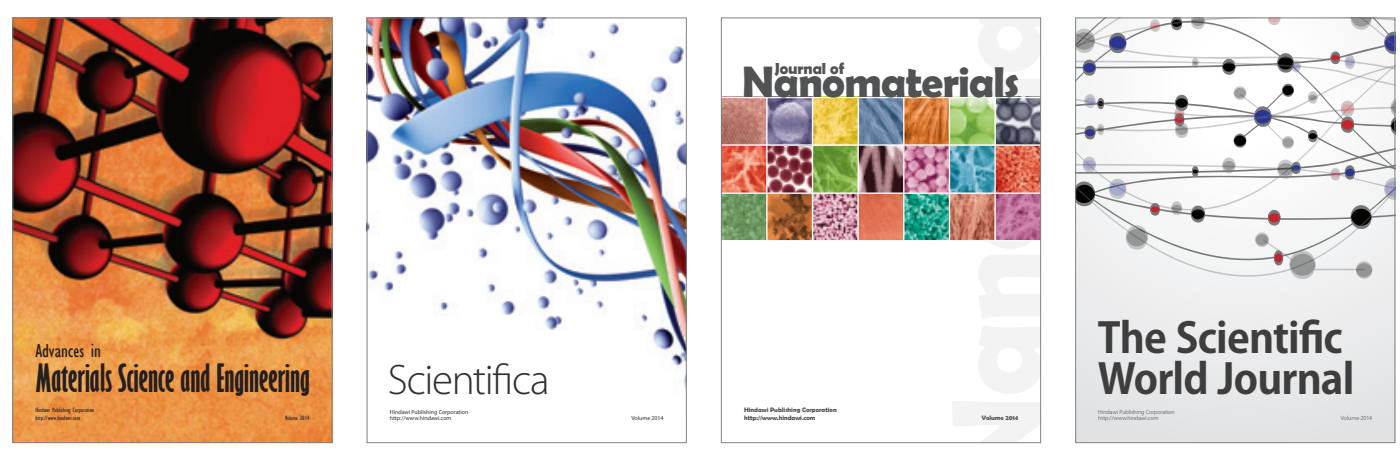

\section{The Scientific World Journal}
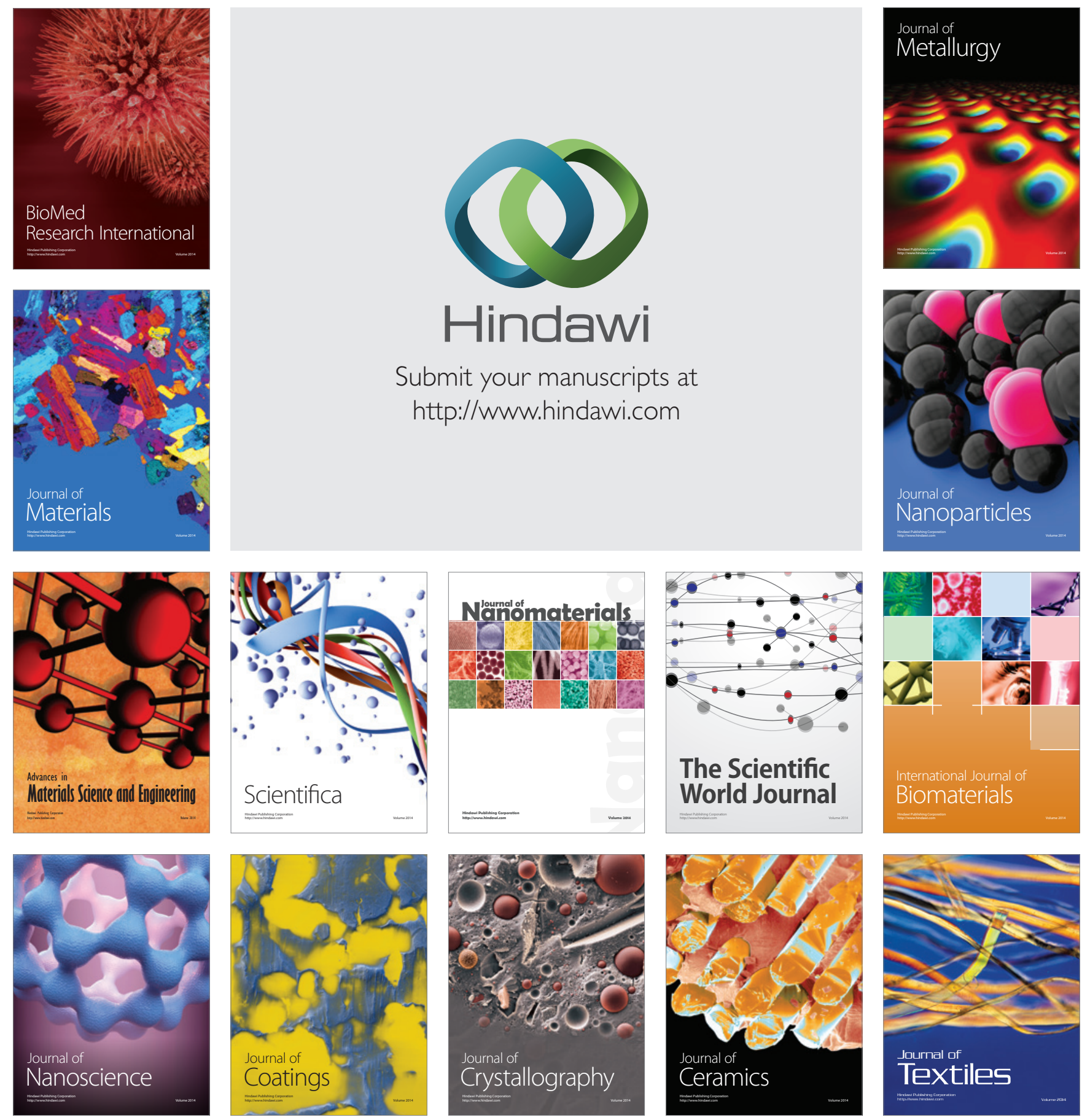